\title{
Congenital Disorders of Deficiency in Glycosaminoglycan Biosynthesis
}

\author{
Shuji Mizumoto* and Shuhei Yamada \\ Department of Pathobiochemistry, Faculty of Pharmacy, Meijo University, Nagoya, Japan
}

Glycosaminoglycans (GAGs) including chondroitin sulfate, dermatan sulfate, and heparan sulfate are covalently attached to specific core proteins to form proteoglycans, which are distributed at the cell surface as well as in the extracellular matrix. Proteoglycans and GAGs have been demonstrated to exhibit a variety of physiological functions such as construction of the extracellular matrix, tissue development, and cell signaling through interactions with extracellular matrix components, morphogens,

\section{OPEN ACCESS}

Edited by:

Fransiska Malfait,

Ghent University, Belgium

Reviewed by:

Robert Smigiel,

Wrocław Medical University, Poland Nicolina Cristina Sorrentino, Telethon Institute of Genetics and Medicine (T/GEM), Italy

*Correspondence:

Shuji Mizumoto

mizumoto@meijo-u.ac.jp

Specialty section:

This article was submitted to Genetics of Common and Rare

Diseases,

a section of the journal

Frontiers in Genetics

Received: 31 May 2021

Accepted: 12 August 2021

Published: 03 September 2021

Citation:

Mizumoto S and Yamada S (2021) Congenital Disorders of Deficiency

in Glycosaminoglycan Biosynthesis.

Front. Genet. 12:717535.

doi: 10.3389/fgene.2021.717535 cytokines, and growth factors. Not only connective tissue disorders including skeletal dysplasia, chondrodysplasia, multiple exostoses, and Ehlers-Danlos syndrome, but also heart and kidney defects, immune deficiencies, and neurological abnormalities have been shown to be caused by defects in GAGs as well as core proteins of proteoglycans. These findings indicate that GAGs and proteoglycans are essential for human development in major organs. The glycobiological aspects of congenital disorders caused by defects in GAG-biosynthetic enzymes including specific glysocyltransferases, epimerases, and sulfotransferases, in addition to core proteins of proteoglycans will be comprehensively discussed based on the literature to date.

\footnotetext{
Keywords: chondroitin sulfate, dermatan sulfate, heparan sulfate, proteoglycan, glycosaminoglycan, connective tissue disorder, skeletal disorder, skin disorder
}

\section{INTRODUCTION}

Glycosaminoglycans (GAGs), including chondroitin sulfate (CS), dermatan sulfate (DS), and heparan sulfate (HS), are linear polysaccharides that are covalently attached to core proteins, forming proteoglycans (PGs). PGs are ubiquitously distributed on the cell surface and in the extracellular matrix (Iozzo, 1998; Bishop et al., 2007; Thelin et al., 2013; Mizumoto et al., 2015a). GAGs are critically involved in a variety of biological functions including cell adhesion, cellular signaling, and the architecture of the extracellular matrix. A large number of studies have reported analyses of GAGs from various types of cells, nematodes, fruit flies, zebrafish, chicks, and mice (Häcker et al., 2005; Bülow and Hobert, 2006; Mizumoto et al., 2014). After the mapping of the of human genome, congenital disorders caused by defects in GAG biosynthesis have been revealed by many research groups (Mizumoto et al., 2013, 2014, 2015b; Mizumoto, 2018). This review provides a comprehensive overview of genetic disorders with symptoms affecting various 
areas of the body such as bone, skin, brain, heart, and immune system caused by defects in the biosynthesis of GAG side chains of PGs.

\section{BIOSYNTHETIC PATHWAY OF GLYCOSAMINOGLYCANS}

\section{Biosynthesis of Donor Substrates for GAGs and Transporters of Uridine $5^{\prime}$-Diphosphate-Sugars, Sulfate lons, and 3'-Phosphoadenosine 5'-Phosphosulfate}

Most glycosyltransferases and sulfotransferases utilize donor substrates such as uridine $5^{\prime}$-diphosphate (UDP)-sugars and 3'-phosphoadenosine 5'-phosphosulfate (PAPS), respectively. The nucleotide sugars, UDP-Glc, UDP-GlcA, UDP-GlcNAc, UDP-GalNAc, UDP-Gal, and UDP-Xyl, where Glc, GlcA, GlcNAc, GalNAc, Gal, and Xyl, represent D-glucose, D-glucuronic acid, $N$-acetyl-D-glucosamine, $N$-acetyl-Dgalactosamine, $\mathrm{D}$-galactose, and $\mathrm{D}$-xylose, respectively, are produced predominantly from Glc, D-glucosamine (GlcN), and D-Gal (Figure 1). UDP-GlcA is formed by the action of the UDP-Glc dehydrogenase on UDP-Glc in the cytosol (Spicer et al., 1998). UDP-Xyl is formed by the action of UDPGlcA decarboxylase/UDP-xylose synthase in the endoplasmic reticulum and Golgi apparatus (Moriarity et al., 2002). These UDP-sugars mainly synthesized in the cytosol, except for UDP-Xyl, are incorporated into the endoplasmic reticulum and Golgi lumen through nucleotide sugar transporters (Figure 1; Berninsone and Hirschberg, 2000).

Various GAG sulfotransferases catalyze the transfer of the sulfate group from the donor substrate, PAPS, to respective acceptor substrates (Kusche-Gullberg and Kjellén, 2003). PAPS is formed from adenosine $5^{\prime}$-triphosphate (ATP) and inorganic sulfate, which is incorporated into the cytosol through the sulfate transporter at the plasma membrane (Figure 1; Hästbacka et al., 1994). PAPS synthase (PAPSS) is a dual enzyme containing ATP sulfurylase and adenosine $5^{\prime}$-phosphosulfate kinase domains at C- and N-terminals, respectively (Venkatachalam, 2003).

\section{Glycosaminoglycan Backbones}

The biosynthesis of the linker region tetrasaccharide in CS, DS, and HS, but not keratan sulfate (KS) is initiated by the transfer of a xylose (Xyl) from UDP-Xyl to the specific serine residues on the core proteins of PGs by xylosyltransferase (XylT) encoded by XYLT1 and XYLT2 in the endoplasmic reticulum (Table 1; Götting et al., 2000; Pönighaus et al., 2007). Thereafter, galactosyltransferase-I (GalT-I), galactosyltransferase-II (GalTII), and glucuronosyltransferase-I (GlcAT-I), which are encoded by B4GALT7, B3GALT6, and B3GAT3, respectively, transfer two galactoses (Gals) and a glucuronic acid (GlcA) from UDPGal and UDP-GlcA to the Xyl residues in the Golgi apparatus (Figure 2A; Kitagawa et al., 1998; Almeida et al., 1999; Okajima et al., 1999; Bai et al., 2001). Modifications in the linker region tetrasaccharide, including the 2-O-phosphorylation of the Xyl residue as well as sulfation at the C- 6 position of the first
Gal and at C- 4 or C- 6 of the second Gal residue, have been reported (Sugahara and Kitagawa, 2000). These modifications are catalyzed by GAG-Xyl 2-O-kinase, Xyl 2-O-phosphatase, and Gal-6-O-sulfotransferase encoded by FAM20B, ACPL2, and CHST3, respectively (Kitagawa et al., 2008; Koike et al., 2009, 2014), and affect the glycosyltransferase reactions of GalT-I and GlcAT-I in vitro, which may regulate the biosynthesis of GAG chains (Gulberti et al., 2005; Tone et al., 2008).

The CS-repeating disaccharide region, [GlcA-Nacetyl-galactosamine (GalNAc) $]_{n}$, is constructed by chondroitin synthases (CHSYs) including CHSY1, CHSY3, chondroitin polymerizing factor (CHPF), CHPF2, CS $\mathrm{N}$-acetylgalactosaminyltransferase 1 (CSGALNACT1), and CSGALNACT2 using UDP-GlcA and UDP-GalNAc as donor substrates in the Golgi apparatus (Figure 2A and Table 2; Kitagawa et al., 2001, 2003; Uyama et al., 2002, 2003; Izumikawa et al., 2007, 2008).

The DS-repeating disaccharide region, [iduronic acid (IdoA)GalNAc $]_{n}$, is formed by the epimerization of the C-5 position of GlcA residues in a chondroitin as a precursor molecule (Figure 2A; Maccarana et al., 2006; Pacheco et al., 2009).

The repeating disaccharide region of $\mathrm{HS}$, $[\mathrm{GlcA}-\mathrm{GlcNAc}]_{n}$, is assembled by exostosin (EXT) family proteins such as EXT1, EXT2, EXT-like 1 (EXTL1), EXTL2, and EXTL3 using UDP-GlcA and UDP-GlcNAc as donor substrates in the Golgi apparatus (Figure 2A and Table 3; Lind et al., 1998; McCormick et al., 1998; Kitagawa et al., 1999; Kim et al., 2001, 2003). After the formation of these polymers, various sulfotransferases transfer a sulfate group to the respective hydroxy and/or amino group in CS, DS, and HS, which gives rise to functional domains to interact with a wide range of proteins (Figure 3 and Tables 2, 3; Kusche-Gullberg and Kjellén, 2003).

The repeating disaccharide region of KS, [Gal-GlcNAc $]_{n}$, is assembled by GalT and GlcNAcT encoded by B4GALT4 and B3GNT7, respectively (Figure 2B; Seko et al., 2003; Seko and Yamashita, 2004; Kitayama et al., 2007). Further modification by sulfation on Gal and GlcNAc residues occurs by the action of KS Gal 6-O-sulfotransferase and GlcNAc 6-O-sulfotransferase encoded by CHST1 and CHST5 as well as CHST6, respectively (Figure 3 and Table 4; Fukuta et al., 1997; Akama et al., 2001, 2002; Narentuya et al., 2019).

\section{PROTEOGLYCAN LINKEROPATHY}

The disturbance of construction of the linker region tetrasaccharide, -O-Xyl-Gal-Gal-GlcA, in CS, DS, and HS by mutations in XYLT1, XYLT2, B4GALT7, B3GALT6, and B3GAT3 causes the hereditary disease "Proteoglycan linkeropathy," which is characterized by abnormalities in connective tissue, bone, skin, and heart (Table 1). Proteoglycan linkeropathy, designated by Dr. Shiro IKEGAWA, is a collective term for diverse connective tissue disorders caused by mutations in these genes (Nakajima et al., 2013). Nosology and classification of skeletal disorders and Ehlers-Danlos syndrome (EDS) are referred to in the Nosology and classification of genetic skeletal disorders: 2019 revision and 2017 International Classification of 


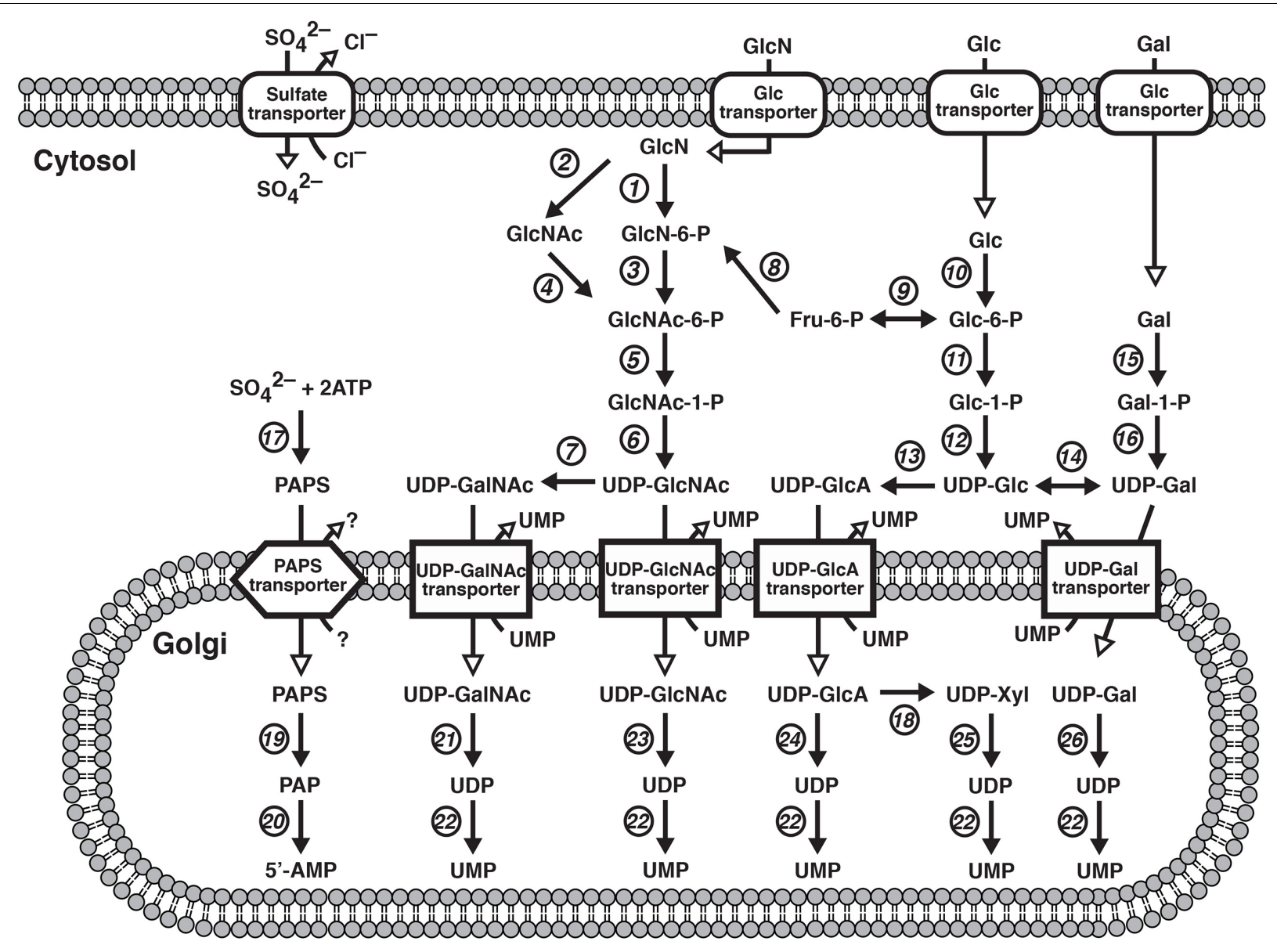

FIGURE 1 | Biosynthetic pathways of UDP-sugars and PAPS. 1, Hexokinase; 2, GlcNH 2 acetyltransferase; 3, GlcNH 2 6-phosphate N-acetyltransferase; 4, GlcNAc kinase; 5, GlcNAc phosphomutase; 6, UDP-GlcNAc pyrophosphorylase: 7, UDP-GalNAc 4-epimerase; 8, glutamine-fructose-6-phosphate aminotransferase; 9 , Glc-6-phosphate isomerase; 10, hexokinase; 11, phosphoglucomutase; 12, UDP-Glc pyrophosphorylase; 13, UDP-Glc dehydrogenase; 14, UDP-Glc 4-epimerase; 15, galactokinase; 16, Gal-1-phosphate uridylyltransferase; 17, PAPS synthase; 18, UDP-GlcA decarboxylase; 19, sulfotransferases; 20, adenosine-3', 5'-bisphosphate 3'-phosphatase; 21, GalNAc transferases; 22, nucleoside 5'-diphosphate phosphatase; 23, GlcNAc transferases; 24, GlcA transferases; 25, Xyl transferases; 26, Gal transferases.

the Ehlers-Danlos syndromes, respectively (Malfait et al., 2017, 2020; Mortier et al., 2019).

\section{Disorders Caused by Mutations of XYLT1 and $X Y L T 2$}

XYLT1 transfers a Xyl residue from UDP-Xyl to the serine residue on the specific core proteins of PGs (Figure 2A; Götting et al., 2000). Desbuquois dysplasia type 2 is an autosomal recessive disorder that is characterized by severe pre- and postnatal growth retardation, a short stature, joint laxity, the dislocation of large joints, and a flat face with prominent eyes (Table 1; Desbuquois et al., 1966), and is caused by mutations in XYLT1 (Bui et al., 2014; Silveira et al., 2016; Al-Jezawi et al., 2017; Guo et al., 2017a). Fibroblasts from patients (p.Arg147*) show reduced CS rather than HS (Bui et al., 2014), which may indicate that the loss-of-function in XYLT1 affects the biosynthesis of CS rather than HS.
Autosomal recessive short stature syndrome was also caused by a homozygous mutation (p.Arg481Trp) in XYLT1 (Schreml et al., 2014). Although XYLT1 in control cells was located in the Golgi apparatus, p.Arg481Trp-XYLT1 was diffusely distributed throughout the cytoplasm with partial localization to the Golgi apparatus in patients' fibroblasts (Schreml et al., 2014). Furthermore, decorin-PG from the fibroblasts of a patient was partially deglycanated (Schreml et al., 2014).

Baratela-Scott syndrome is an autosomal recessive disorder characterized by a short stature, patellar dislocation, short tubular bones, mild metaphyseal changes, brachymetacarpalia with stub thumbs, short femoral necks, shallow acetabular roofs, platyspondyly, a flattened midface with broad nasal bridge, cleft palate, bifid uvula, and synophrys (Baratela et al., 2012). This disease is caused by homozygous mutations in XYLT1, homozygous hypermethylation of exon 1 in XYLT1 that is caused by a GGC repeat expansion in the XYLT1 promoter region, or a 
TABLE 1 | Congenital disorders of GAG-linker region tetrasaccharide deficiency*.

\begin{tabular}{|c|c|c|c|c|}
\hline Gene & Protein $* *$ & $\begin{array}{l}\text { Chromosomal } \\
\text { location }\end{array}$ & MIM number & Name of disorder \\
\hline \multirow[t]{2}{*}{$X Y L T 1$} & XylT1 & $16 p 12.3$ & $\begin{array}{l}615777 \\
608124\end{array}$ & Desbuquios dysplasia type 2; Short stature syndrome \\
\hline & & & 300881 & Baratela-Scott syndrome \\
\hline$X Y L T 2$ & XylT2 & $17 q 21.33$ & $\begin{array}{l}605822 \\
608125\end{array}$ & Spondyloocular syndrome \\
\hline B4GALT7 & GalT-I & $5 q 35.3$ & $\begin{array}{l}130070 \\
604327\end{array}$ & $\begin{array}{l}\text { Ehlers-Danlos syndrome spondylodysplastic type 1; Ehlers-Danlos } \\
\text { syndrome progeroid type 1; Ehlers-Danlos syndrome with a short }\end{array}$ \\
\hline
\end{tabular}

stature and limb anomalies

Larsen of Reunion Island syndrome

B3GALT6 GalT-II $\quad 1$ 1p36.33 $615349 \quad$ Ehlers-Danlos syndrome spondylodysplastic type 2; Ehlers-Danlos $615291 \quad$ syndrome progeroid type 2

271640 Spondyloepimetaphyseal dysplasia with joint laxity type 1

$\begin{array}{lll}\text { B3GAT3 GlcAT-I } & 11 \mathrm{q} 12.3 \quad & 245600 \\ & 606374\end{array}$

$264180 \quad$ Pseudodiastrophic dysplasia

FAM2OB Xylosylkinase (GXK1) 1925.2

611063

Severe (lethal) neonatal short limb dysplasia with multiple dislocations

Clinical hallmarks

A short stature, joint laxity, advanced carpal ossification, a flat face with prominent eyes, and hand anomalies.

A short stature, patellar dislocation, short tubular bones, mild metaphyseal changes, brachymetacarpalia with stub thumbs, short femoral necks, shallow acetabular roofs, platyspondyly, flattened midface with broad nasal bridge, cleft palate, bifid uvula, and synophrys.

Osteoporosis, cataracts, sensorineural hearing loss, and mild learning defects.

Developmental delay, aged appearance, a short stature, craniofacial dysmorphism, defective wound healing with atrophic scars, generalized osteopenia, joint hypermobility, radioulnar synostosis, severe hypermetropia, blue sclerae, refractive, errors, corneal clouding, strabismus, nystagmus, cataracts, glaucoma, and retinal abnormalities.

Multiple dislocations, hyperlaxity, dwarfism, and distinctive facial features.

A short stature, joint laxity and dislocation, facial dysmorphism, joint contractures, severe bone fragility with multiple fractures, spondyloepimetaphyseal dysplasia, and intellectual disability.

Spatulate fingers with short nails, hip dislocation, elbow contracture, clubfeet, and mild craniofacial dysmorphism including prominent eyes, blue sclera, a long upper lip, and a small mandible with cleft palate.

Multiple joint dislocations, a short stature, craniofacial dysmorphism Joint dislocations mainly affecting the elbow, congenital heart defects (a with or without congenital heart defects; Larsen-like syndrome B3GAT3 type; B3GAT3-related disorder with dislocation and congenital heart defects

B3GAT3-related disorder with cutis laxa and bone fragility

B3GAT3-related disorder with craniosynostosis and bone fragility bicuspid aortic valve and aortic root dilatation), osteoporosis, hypotonia, joint laxity, fractures, scoliosis, a biscuspid aortic valve, and myopia.

Spondyloepimetaphyseal dysplasia, cutis laxa, osteoporosis, fractures, multiple bony chondromas, and a short stature.

Craniosynostosis, midface hypoplasia with proptosis, long tapered fingers, elbow joint contracture due to radioulnar synostosis, and an equinovarus position of the feet.

Prenatal manifestation, early lethality, short-limbed short stature at birth, facial dysmorphism, and distinctive skeletal abnormalities including short ribs, mild to moderate platyspondyly, broad ilia with flaring, increased acetabular angle, shortened long bones with metaphyseal flaring, elongation of the proximal and middle phalanges with subluxation of the proximal interphalangeal joints, subluxation of the elbow, and talipes equinovarus. Neonatal lethality, mid-face hypoplasia, thoracic hypoplasia with respiratory failure, a very short stature with mesomelic shortening of the limbs, and multiple dislocations of large joints.

*, the table was cited from a reference (Mizumoto, 2018) with modifications.

**, or enzymatic activity.

MIM, Mendelian inheritance in man; XYLT, xylosyltransferase; B4GALT7, xylosylprotein beta 1,4-galactosyltransferase 7; B3GALT6, beta 1,3-galactosyltransferase 6; B3GAT3, beta 1,3-glucuronyltransferase 3; FAM20B, Family with sequence similarity 20 member $B$. 


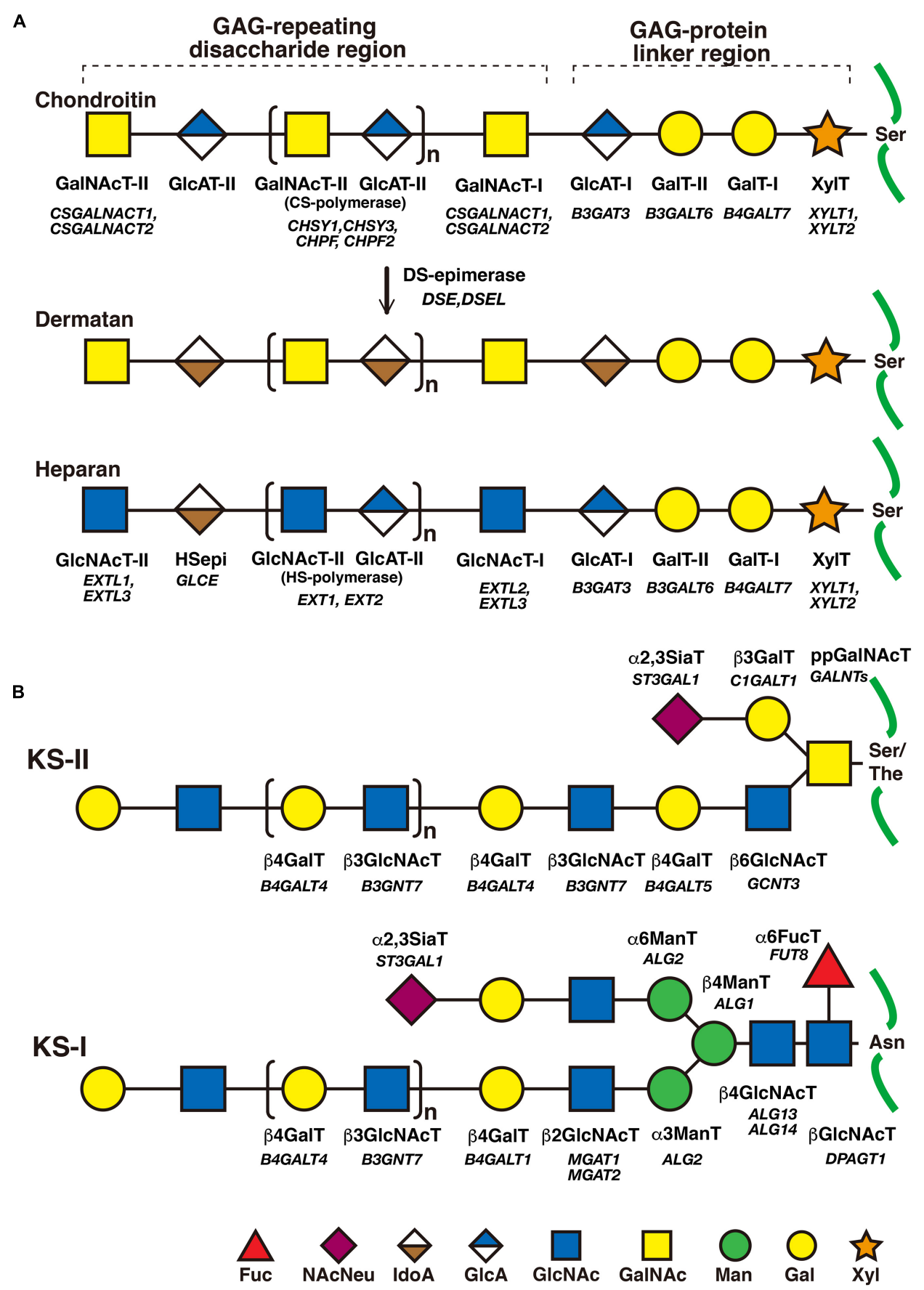

FIGURE 2 | The biosynthetic assembly of GAGs. (A) Schematic presentation of the biosynthesis of CS, DS, and HS. Following the synthesis of specific core proteins of proteoglycans, the common GAG-linker region tetrasaccharide (CS, DS, and HS except for KS), GlcA-Gal-Gal-Xyl-O-, is built up by the consecutive addition of each sugar moiety from the respective UDP-sugar, including UDP-Xyl, UDP-Gal, or UDP-GlcA, by XyIT, GalT-I, GalT-II, and GlcAT-I. The first GalNAc residue is then transferred to the GlcA residue at the non-reducing end in the linker region by GalNAcT-I, which initiates the construction of the chondroitin backbone. The repeating disaccharide region (chondroitin backbone of CS), [-3GalNAc $\beta 1-4 G l c A \beta 1-]_{n}$, is elongated by alternate additions of GlcA and GalNAc residues from UDP-GlcA and UDP-GalNAc catalyzed by CS-GlcAT-II and GalNAcT-II activities, respectively. After or during the formation of the chondroitin backbone, DSE converts GlcA into IdoA by epimerizing the C- 5 carboxy group, resulting in the formation of the dermatan backbone of DS, [-3GalNAc $\beta 1-4 l d o U A \alpha 1-]_{n}$. Alternatively, the first GlcNAc residue is transferred to the GlcA residue at the non-reducing end in the linker region by GlcNAcT-I, which initiates the construction of the heparan backbone. The repeating disaccharide region (heparan backbone of HS), [-4GlcNAca1-4GlcA 1 1- $]_{n}$, is elongated by alternate additions of the GlcA and GlcNAc residues from UDP-GlcA and UDP-GIcNAc catalyzed by HS-GICAT-II and GlcNAcT-II activities, respectively. (B) Schematic presentation of the biosynthesis of KS. After the formation of the linkage region of $\mathrm{KS}, \mathrm{O}$ - and $\mathrm{N}$-linked oligosaccharides, the repeating disaccharide region, [-4GlcNAc $\beta 1-3 \mathrm{Gal} \beta 1$ - $]_{n}$, is elongated by alternate additions of the Gal and GlcNAc residues from UDP-Gal and UDP-GIcNAc catalyzed by $\beta 4$ GalT and $\beta 3 G$ GcNAcT activities, respectively. Each enzyme and its coding gene are described under the respective sugar symbols from the top of each line. 
TABLE 2 | Congenital disorders of CS and DS deficiencies*

\begin{tabular}{|c|c|c|c|c|c|}
\hline Gene & Protein & $\begin{array}{l}\text { Chromosomal } \\
\text { location }\end{array}$ & MIM number & Name of disorder & Clinical hallmarks \\
\hline CHSY1 & ChSy1 (GalNAcT-II, CS-GIcAT-II) & $15 q 26.3$ & $\begin{array}{l}605282 \\
608183\end{array}$ & Temtamy preaxial brachydactyly syndrome & $\begin{array}{l}\text { A short stature, bilateral, symmetric preaxial } \\
\text { brachydactyly and hyperphalangism of the digits, facial } \\
\text { dysmorphism, dental anomalies, sensorineural hearing } \\
\text { loss, delayed motor and mental development, and } \\
\text { growth retardation. }\end{array}$ \\
\hline CSGALNACT1 & CSGalNAcT1 (GalNAcT-I, GalNAcT-II) & $8 p 21.3$ & 616615 & $\begin{array}{l}\text { Skeletal dysplasia, mild, with joint laxity and advanced } \\
\text { bone age }\end{array}$ & $\begin{array}{l}\text { Brachydactyly, joint laxity, mild facial dysmorphism } \\
\text { consisting of midface hypoplasia, a flat nasal bridge, } \\
\text { short nose, anteverted nares, a long philtrum, and } \\
\text { microretrognathia. }\end{array}$ \\
\hline DSE & DS-epimerase-1 & $6 q 22.1$ & $\begin{array}{l}615539 \\
605942\end{array}$ & Ehlers-Danlos syndrome musculocontractural type 2 & $\begin{array}{l}\text { Characteristic facial features, congenital contracture of } \\
\text { the thumbs and feet, hypermobility of the finger, elbow, } \\
\text { and knee joints, atrophic scarring of the skin, and } \\
\text { myopathy. }\end{array}$ \\
\hline \multirow[t]{2}{*}{ DSEL } & DS-epimerase-2 & $18 q 22.1$ & 611125 & Bipolar disorder; Depressive disorder & $\begin{array}{l}\text { Alternating episodes of depression and mania or } \\
\text { hypomania. }\end{array}$ \\
\hline & & & & Diaphragmatic hernia; Microphthalmia & $\begin{array}{l}\text { Diaphragmatic hernia, respiratory difficulties, and } \\
\text { microphthalmia. }\end{array}$ \\
\hline CHST3 & C6ST-1 & 10q22.1 & $\begin{array}{l}143095 \\
603799\end{array}$ & $\begin{array}{l}\text { Spondyloepiphyseal dysplasia with congenital joint } \\
\text { dislocations; Spondyloepiphyseal dysplasia Omani } \\
\text { type; Chondrodysplasia with multiple dislocations } \\
\text { Megarbane type; Humerospinal dysostosis; Larsen } \\
\text { syndrome autosomal recessive type; Desbuquois } \\
\text { syndrome }\end{array}$ & $\begin{array}{l}\text { A short stature, severe kyphoscoliosis, osteoarthritis } \\
\text { (elbow, wrist, and knee), secondary dislocation of large } \\
\text { joints, rhizomelia, fusion of carpal bones, mild } \\
\text { brachydactyly, metacarpal shortening, ventricular septal } \\
\text { defect, mitral and tricuspid defects, aortic regurgitation, } \\
\text { and deafness. }\end{array}$ \\
\hline CHST11 & C4ST-1 & $12 q 23.3$ & $\begin{array}{l}610128 \\
618167\end{array}$ & $\begin{array}{l}\text { Osteochondrodysplasia, brachydactyly, and } \\
\text { overlapping malformed digits }\end{array}$ & $\begin{array}{l}\text { Brachydactyly, overriding digits and } \\
\text { clinosymphalangism in hands and feet, and syndactyly } \\
\text { and hexadactyly in feet, scoliosis, dislocated patellae, } \\
\text { and fibulae and pectus excavatum. }\end{array}$ \\
\hline CHST14 & D4ST-1 & $15 q 15.1$ & $\begin{array}{l}601776 \\
608429\end{array}$ & $\begin{array}{l}\text { Ehlers-Danlos syndrome musculocontractural type 1; } \\
\text { Ehlers-Danlos syndrome, type VIB; Adducted } \\
\text { thumb-clubfoot syndrome }\end{array}$ & $\begin{array}{l}\text { Craniofacial dysmorphism, multiple contractures, } \\
\text { progressive joint and skin laxities, multisystem } \\
\text { fragility-related manifestations, contracture of the } \\
\text { thumbs and feet, defects of the heart, kidneys, and } \\
\text { intestines. }\end{array}$ \\
\hline UST & CS/DS2ST & $6 q 25.1$ & 610752 & $\begin{array}{l}\text { Multiple congenital anomalies of the heart and central } \\
\text { nervous system }\end{array}$ & $\begin{array}{l}\text { Growth failure, congenital heart defects, and } \\
\text { underdeveloped cerebellar vermis, abnormal cutaneous } \\
\text { elasticity, and joint laxity. }\end{array}$ \\
\hline
\end{tabular}


TABLE 3 | Congenital disorders of HS deficiency*.

\begin{tabular}{|c|c|c|c|c|c|}
\hline Gene & Protein & $\begin{array}{l}\text { Chromosomal } \\
\text { location }\end{array}$ & MIM number & Name of disorder & Clinical hallmarks \\
\hline \multirow[t]{2}{*}{ EXT1 } & $\begin{array}{l}\text { HS- } \\
\text { polymerase-1 } \\
\text { (GlcNAcT-II } \\
\text { HS-GlcAT-II) }\end{array}$ & $8 q 24.11$ & $\begin{array}{l}133700 \\
215300 \\
608177\end{array}$ & $\begin{array}{l}\text { Exostoses multiple type 1; } \\
\text { Chondrosarcoma }\end{array}$ & $\begin{array}{l}\text { The formation of cartilage-capped tumors } \\
\text { (exostoses) that develop from the growth } \\
\text { plate of endochondral bones, particularly } \\
\text { long bones. }\end{array}$ \\
\hline & & & 150230 & $\begin{array}{l}\text { Trichorhinophalangeal syndrome, type } \\
\text { II; Langer-Giedion syndrome }\end{array}$ & $\begin{array}{l}\text { Craniofacial dysmorphism, exostoses, } \\
\text { sparse scalp hair, bushy eyebrows, a } \\
\text { bulbous nose, long philtrum, short } \\
\text { stature, and cone-shaped epiphyses } \\
\text { (This disorder was caused by deletion } \\
\text { encompassing EXT2 and TRPS1.) }\end{array}$ \\
\hline \multirow[t]{2}{*}{ EXT2 } & $\begin{array}{l}\text { HS- } \\
\text { polymerase-2 } \\
\text { (GlcNAcT-II } \\
\text { HS-GlcAT-II) }\end{array}$ & $11 \mathrm{p} 11.2$ & $\begin{array}{l}133701 \\
608210\end{array}$ & Exostoses multiple type 2 & $\begin{array}{l}\text { The formation of cartilage-capped tumors } \\
\text { (exostoses) that develop from the growth } \\
\text { plate of endochondral bones, particularly } \\
\text { long bones. }\end{array}$ \\
\hline & & & 601224 & Potocki-Shaffer syndrome & $\begin{array}{l}\text { Multiple exostoses, bilateral parietal } \\
\text { foramina, intellectual disability, hearing } \\
\text { loss, craniofacial dysmorphisms, } \\
\text { cardiovascular, ocular, and genitourinary } \\
\text { tract abnormalities (This disorder was } \\
\text { caused by deletion encompassing EXT2 } \\
\text { and eight other genes.) }\end{array}$ \\
\hline EXTL3 & $\begin{array}{l}\text { EXTL3 } \\
\text { (GlcNAcT-I, } \\
\text { GlcNAcT-II) }\end{array}$ & $8 p 21.1$ & $\begin{array}{l}617425 \\
605744\end{array}$ & $\begin{array}{l}\text { Immunoskeletal dysplasia with } \\
\text { neurodevelopmental abnormalities; } \\
\text { Neuro-immuno-skeletal dysplasia } \\
\text { syndrome; Spondyloepimetaphyseal } \\
\text { dysplasia with immunodeficiency }\end{array}$ & $\begin{array}{l}\text { Severe combined immunodeficiency with } \\
\text { a complete absence of T cells, intellectual } \\
\text { disability, a short stature, limb shortening, } \\
\text { dysmorphic facial features, and skeletal } \\
\text { abnormalities such as severe } \\
\text { platyspondyly, lumbar gibbus, and } \\
\text { kyphoscoliosis. }\end{array}$ \\
\hline HS2ST1 & HS2ST-1 & $1 \mathrm{p} 22.3$ & $\begin{array}{l}604844 \\
619194\end{array}$ & $\begin{array}{l}\text { Neurofacioskeletal syndrome with or } \\
\text { without renal agenesis }\end{array}$ & $\begin{array}{l}\text { Facial dysmorphism with a coarse face, } \\
\text { upslanted palpebral fissures, broad nasal } \\
\text { tip, and wide mouth, developmental delay } \\
\text { and/or intellectual disability, corpus } \\
\text { callosum agenesis or hypoplasia, flexion } \\
\text { contractures, brachy- dactyly of hands } \\
\text { and feet with broad fingertips and toes, } \\
\text { and uni- or bilateral renal agenesis. }\end{array}$ \\
\hline HS6ST1 & HS6ST-1 & $2 q 14.3$ & $\begin{array}{l}614880 \\
604846\end{array}$ & $\begin{array}{l}\text { Hypogonadotropic hypogonadism } 15 \\
\text { with or without anosmia; Kallmann } \\
\text { syndrome }\end{array}$ & $\begin{array}{l}\text { Lack of sexual maturation, low levels of } \\
\text { circulating gonadotropins and } \\
\text { testosterone, and anosmia. }\end{array}$ \\
\hline SULF1 & $\begin{array}{l}\mathrm{HS} 6-\mathrm{O}- \\
\text { endosulfatase- } \\
1\end{array}$ & $8 q 13.2-q 13.3$ & 610012 & Mesomelia-synostoses syndrome & $\begin{array}{l}\text { Mesomelic limb shortening, acral } \\
\text { synostoses, and multiple congenital } \\
\text { malformations (This disorder was caused } \\
\text { by deletion } 582-738 \mathrm{~kb} \text { in size } \\
\text { encompassing SULF1 and SLCO5A1.) }\end{array}$ \\
\hline
\end{tabular}

*, the table was cited from a reference (Mizumoto, 2018) with modifications.

EXT, exostosin; EXTL, exostosin-like; NDST, N-deacetylase/N-sulfotransferase; HS2ST, heparan sulfate 2-O-sulfotransferase; HS6ST, heparan sulfate 6-Osulfotransferase. 


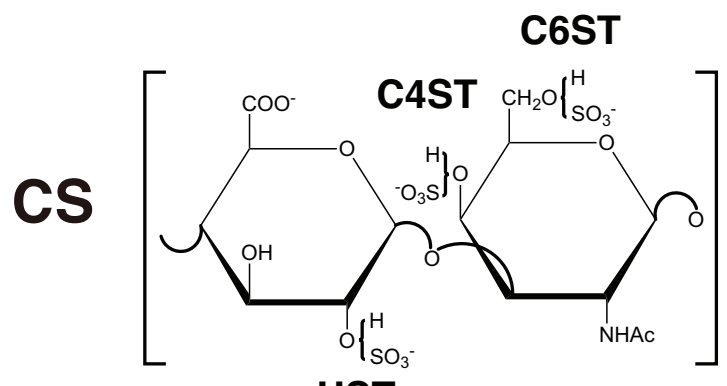

UST

[-4GIcA $\beta 1-3 G$ alNAc $\beta 1-]$

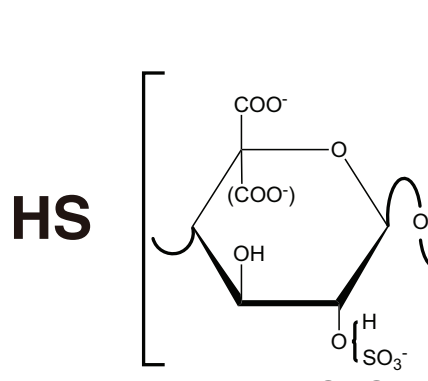

HS2ST

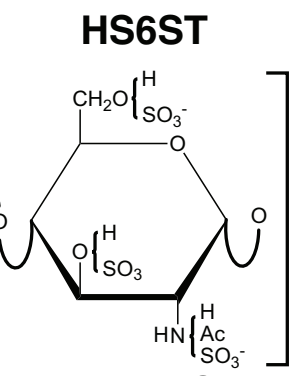

NDST

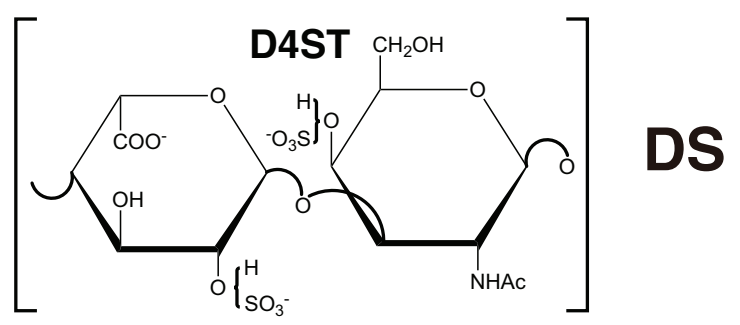

UST

\section{[-4IdoA $\alpha 1-3$ GaINAc $\beta 1$-]}

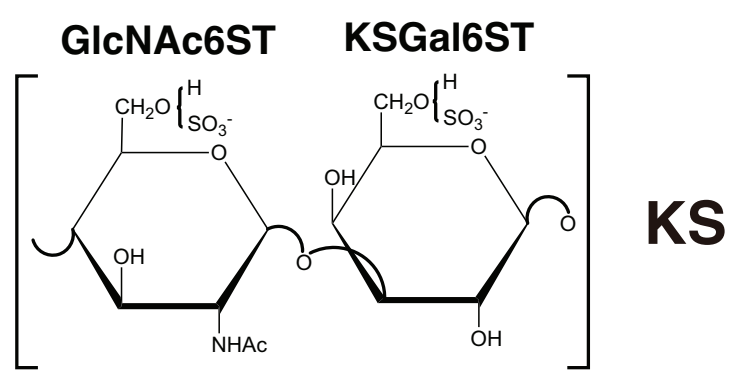

\section{[-4GIcNAc $\beta 1-3 G a l \beta 1-]$}

FIGURE 3 | Typical repeating disaccharide units in GAGs and the respective sulfotransferase. The CS backbone consists of GlcA and GalNAc, whereas DS is a stereoisomer of CS that includes IdoA instead of GlcA. HS consist of uronic acids (IdoA and GlcA) and GlcNAc/GlcNH 2 residues with varying proportions of IdoA and GlcA. These sugar residues can be esterified by sulfate at various positions as indicated in the figure by action of the respective sulfotransferase, which transfers the sulfate group from the sulfate donor $3^{\prime}$-phosphoadenosine $5^{\prime}$-phosphosulfate (PAPS) to the respective hydroxygroup of each residue.

heterozygous 3.1 Mbp deletion on 16p13 encompassing XYLT1 with hypermethylation (LaCroix et al., 2019).

Homozygous mutations in XYLT2 cause spondyloocular syndrome that is characterized by retinal detachment, amblyopia, nystagmus, hearing loss, heart septal defects, bone fragility, and mild learning difficulties (Table 1; Munns et al., 2015; Taylan et al., 2016, 2017; Umair et al., 2018). The levels of GAGs and XYLT activity in the dermal fibroblasts of a patient were lower than those of healthy subjects (Munns et al., 2015).

The different clinical manifestations between Desbuquois skeletal dysplasia type 2 and spondyloocular syndrome may indicate that XYLT1 and XYLT2 do not compensate for each other, and that the serine residue(s) of the respective core protein as a substrate for each XYLT and spatiotemporal expression may be distinct between XYLT1 and XYLT2.

\section{Severe (Lethal) Neonatal Short Limb Dysplasia With Multiple Dislocations Caused by Mutations in FAM2OB}

FAM20B encodes a kinase, which phosphorylates a Xyl residue in the linker region tetrasaccharide of GAGs
(Koike et al., 2009). Compound heterozygous mutations (p.Thr59Alafs*19/p.Asn347Metfs*4) in FAM20B cause neonatal short limb dysplasia resembling Desbuquois dysplasia (Table 1; Kuroda et al., 2019). The clinical hallmarks are mid-face hypoplasia, thoracic hypoplasia with respiratory failure, a very short stature with mesomelic shortening of the limbs, multiple dislocations of large joints, and preaxial digital hypoplasia as well as syndactyly, being similar to Desbuquois dysplasia (Kuroda et al., 2019).

\section{Ehlers-Danlos Syndrome Spondylodysplastic Type 1 and Larsen Syndrome Reunion Island Type Caused by Mutations in B4GALT7}

B4GALT7 encodes GalT-I, which transfers the second Gal residue in the linker region tetrasaccharide from UDPGal to the serine-O-Xyl (Figure 2A; Almeida et al., 1999; Okajima et al., 1999). Compound heterozygous and homozygous mutations in B4GALT7 cause Ehlers-Danlos syndrome (EDS) spondylodysplastic type 1 (Table 1; Almeida et al., 1999; Okajima et al., 1999; Malfait et al., 2017, 2020). Patients show various 
TABLE 4 | Congenital disorders of KS deficiency.

\begin{tabular}{|c|c|c|c|c|c|}
\hline Gene & Protein & $\begin{array}{l}\text { Chromosomal } \\
\text { location }\end{array}$ & MIM number & Name of disorder & Clinical hallmarks \\
\hline CHST6 & $\begin{array}{l}\text { Corneal } \\
\text { GlcNAc 6-O- } \\
\text { sulfotransferase }\end{array}$ & $16 q 23.1$ & $\begin{array}{l}605294 \\
217800\end{array}$ & $\begin{array}{l}\text { Macular corneal } \\
\text { dystrophy }\end{array}$ & $\begin{array}{l}\text { Progressive } \\
\text { punctate opacities } \\
\text { in the cornea, } \\
\text { bilateral loss of } \\
\text { vision. }\end{array}$ \\
\hline
\end{tabular}

clinical symptoms including an aged appearance, craniofacial dysmorphism, hypermobile joints, generalized osteopenia, a short stature, hypotonic muscles, defective wound healing, global developmental delays, and scoliosis (Almeida et al., 1999; Guo et al., 2013; Arunrut et al., 2016; Salter et al., 2016; Ritelli et al., 2017; Mihalic Mosher et al., 2019). Skin fibroblasts of patients were shown to be defective for the DS side chain of DS-PGs, decorin and biglycan, and show a marked reduction in GalTI activity in vitro (Quentin et al., 1990; Seidler et al., 2006). Furthermore, fibroblasts from patients exhibited reduced levels of sulfation on HS chains (Götte et al., 2008). Hence, various clinical manifestations in EDS spondylodysplastic type 1 might partially result from defects in not only DS, but also HS. Namely, the reasons why these patients with the same B4GALT7 gene mutations exhibited the wide range of symptoms might be due to the distinct mutational positions in B4GALT7, resulting in the different influence of enzymatic activity and/or intracellular localization of mutant enzymes and in the immature GAGs produced by the mutant enzymes.

Larsen syndrome Reunion Island type is caused by a homozygous mutation in B4GALT7 (Table 1; Cartault et al., 2015). The characteristic symptoms of Larsen syndrome are congenital large-joint dislocations including the hip, elbow, and knee, craniofacial abnormalities, and foot deformities (Larsen et al., 1950). Patients showed similar hallmarks to EDS spondylodysplastic type 1 caused by a mutation in B4GALT7, including dwarfism, distinctive facial features, and hyperlaxity, in addition to the classical symptoms of Larsen syndrome (Cartault et al., 2015). Thus, EDS spondylodysplastic type 1 and Larsen syndrome Reunion Island type may share clinical spectra.

\section{Ehlers-Danlos Syndrome Spondylodysplastic Type 2 and Spondyloepimetaphysial Dysplasia With Joint Laxity Type 1 Caused by Mutations in B3GALT6}

B3GALT6 encodes GalT-II, which transfers the third Gal residue in the linker region tetrasaccharide from UDP-Gal to serine-OXyl-Gal (Figure 2A; Bai et al., 2001). Compound heterozygous mutations in B3GALT6 cause EDS spondylodysplastic type 2, which is characterized by kyphoscoliosis, clubfeet, elbow malalignment, muscle hypotonia, wrinkled skin, and a characteristic facial appearance (Table 1; Malfait et al., 2013, 2020; Nakajima et al., 2013). Skin fibroblast cultures from patients produced less CS, DS, and HS than those from control cells (Malfait et al., 2013).
Spondyloepimetaphyseal dysplasia with joint laxity type 1 is also caused by compound heterozygous mutations in B3GALT6 (Table 1; Nakajima et al., 2013; Ritelli et al., 2014; Vorster et al., 2015; Alazami et al., 2016). Spondyloepimetaphyseal dysplasia with joint laxity type 1 is characterized by kyphoscoliosis, joint laxity, hip dislocation, elbow contracture, platyspondyly, clubfeet, and craniofacial dysmorphisms (Beighton et al., 1984). The recombinant mutant enzymes showed a significantly lower GalTII activity than wild-type B3GALT6 (Nakajima et al., 2013). Furthermore, the production of HS and CS/DS in cultured lymphoblastoid cells from patients was shown to be lower and higher, respectively, than that in normal cells (Nakajima et al., 2013). In addition, the levels of HS and HS-PG, perlecan, were markedly lower in cultured fibroblasts from patients than those from normal subjects, whereas the levels of CS-PG and DS-PG, versican and decorin, respectively, in the fibroblasts of patients corresponded to the fibroblasts of normal subjects (Ritelli et al., 2014). These findings suggest that the causative mutations of spondyloepimetaphyseal dysplasia with joint laxity type 1 may affect the biosynthesis of only HS, and not CS or DS, which results in the skeletal and joint hallmarks of both disorders.

\section{Disorders Caused From B3GAT3 Mutations}

B3GAT3 encodes GlcAT-I, which transfers the 4th GlcA residue in the linker region tetrasaccharide, Xyl-Gal-Gal-GlcA, from UDP-GlcA to the serine-O-Xyl-Gal-Gal (Figure 2A; Kitagawa et al., 1998). Homozygous mutations in B3GAT3 cause multiple joint dislocations, a short stature, kyphoscoliosis, craniofacial dysmorphism, and heart defects including bicuspid aortic valve and aortic root dilatation (Table 1; Baasanjav et al., 2011; von Oettingen et al., 2014; Budde et al., 2015). GlcATI activity and the levels of CS, DS, and HS in fibroblasts from these patients were significantly lower than those in the fibroblasts of control cells (Baasanjav et al., 2011; Budde et al., 2015). Other homozygous mutations in B3GAT3 caused distinct hallmarks such as a short stature, spondyloepimetaphyseal dysplasia, osteoporosis, fractures, multiple bony chondromas, cutis laxa, blue sclerae, glaucoma, bilateral radio-ulnar synostosis, severe osteopenia, bilateral clubfeet, atrial and ventricular septal defects, hypertelorism, a small chest, diaphragmatic hernia, arachnodactyly, hypotonia, hearing loss, and perinatal cerebral infarction with bilateral supra- and infratentorial subdural hematomas (Jones et al., 2015; Alazami et al., 2016). Moreover, a patient with the compound heterozygous mutation in B3GAT3 
exhibited severe osteoporosis, fractures, scoliosis, joint laxity, hypotonia, a bicuspid aortic valve, and myopia (Job et al., 2016).

Compound heterozygous mutation in B3GAT3 causes pseudodiastrophic dysplasia, which is associated with prenatal manifestation and early lethality (Table 1; Byrne et al., 2020). Pseudodiastrophic dysplasia is characterized by a short stature at birth, facial dysmorphism, and distinctive skeletal abnormalities including short ribs, platyspondyly, broad ilia with flaring, an increased acetabular angle, shortened long bones with metaphyseal flaring, elongation of the proximal and middle phalanges with subluxation of the proximal interphalangeal joints, subluxation of the elbow, and talipes equinovarus (Eteson et al., 1986; Fischetto et al., 1997; Yap et al., 2016). GlcAT-I activity of fibroblasts from a patient was markedly lower than that from healthy control cells (Byrne et al., 2020). Accordingly, the levels of CS, DS, and HS from the patient cells were significantly decreased compared with control cells (Byrne et al., 2020). Thus, this mutation, p.Arg169Trp/Arg225X, may be a complete loss of function of B3GAT3, which is responsible for the most severe and lethal manifestation of skeletal dysplasia.

Yauy et al. (2018) proposed the classification of B3GAT3related disorders based on the diverse symptoms of patients with distinct mutations in B3GAT3 (Table 1): (1) "B3GAT3related disorder with joint dislocation and congenital heart defect," which is similar to Larsen syndrome; (2) "B3GAT3related disorder with craniosynostosis and bone fragility," which is similar to Antley-Bixler and Shprintzen-Goldberg syndromes; (3) "B3GAT3-related disorder with cutis laxa and bone fragility," which is similar to geroderma osteodysplastica syndrome; and (4) "B3GAT3-related disorder with intermediate phenotype," which is similar to Larsen syndrome and Antley-Bixler/ShprintzenGoldberg syndromes (Yauy et al., 2018). Patients with a broad spectrum of hallmarks caused by mutations in the same B3GAT3 may show various degree of affected biosynthesis of CS, DS, and HS, which is consistent with other linkeropathies. Further analyses using cells from patients with the four types of mutations in B3GAT3 are required to understand the underlying pathogenic mechanisms.

\section{CONGENITAL DISORDERS OF CHONDROITIN SULFATE DEFICIENCY}

\section{Mild Skeletal Dysplasia With Joint Laxity and Advanced Bone Age by Mutations in CSGALNACT1}

CSGALNACT1 encodes $N$-acetylgalactosaminyltransferase-I (GalNAcT-I) and GalNAcT-II, which transfer the 5th GalNAc and subsequent GalNAc residues (7, 9, 11th- - -) from UDPGalNAc to serine-O-Xyl-Gal-Gal-GlcA and [GalNAc-GlcA $]_{n}$, respectively (Figure 2A; Uyama et al., 2002, 2003). Homozygous or compound heterozygous mutations in CSGALNACT1 cause mild skeletal dysplasia, joint laxity, a short stature with an advanced bone age, facial dysmorphism, and mild language delay (Table 2; Vodopiutz et al., 2017; Mizumoto et al., 2020). GalNAcT activity was significantly reduced in fibroblasts from patients. In addition, the amount of CS was decreased in patients' fibroblasts compared with control fibroblasts (Mizumoto et al., 2020).

\section{Temtamy Preaxial Brachydactyly Syndrome Caused by Mutations in CHSY1}

CHSY1 encodes a dual glycosyltransferase, which functions as both GalNAcT-II and CS-GlcAT-II, transferring GalNAc and GlcA residues from UDP-GalNAc and UDP-GlcA, respectively (Figure 2A; Kitagawa et al., 2001, 2003; Izumikawa et al., 2007, 2008). Homozygous or compound heterozygous mutations in CHSY1 cause Temtamy preaxial brachydactyly syndrome, which is characterized by preaxial brachydactyly, hyperphalangism of digits, facial dysmorphism, dental anomalies, sensorineural hearing loss, delayed motor and mental development, and growth retardation (Table 2; Temtamy et al., 1998, 2012; Li et al., 2010; Tian et al., 2010; Sher and Naeem, 2014). The level of CS in a skin section from a patient was lower than that in control skin (Tian et al., 2010). Furthermore, the up-regulated expressions of JAG1 and HES1, whose gene products are ligands of NOTCH and induced by NOTCH signaling, respectively, have been observed (Tian et al., 2010). NOTCH signaling is involved in appendicular skeletal development (Tian et al., 2010). Therefore, a decrease in CS by mutations in CHSY1 may influence changes in the expression of JAG1 and HES1, thereby leading to brachydactyly.

\section{Spondyloepiphyseal Dysplasia With Congenital Joint Dislocations, Larsen Syndrome, and Humero-Spinal Dysostosis Caused by Mutations in CHST3}

CHST3 encodes chondroitin 6-O-sulfotransferase 1 (C6ST1), which transfers a sulfate group from $3^{\prime}$-phosphoadenosine $5^{\prime}$ phosphosulfate (PAPS) to the C-6 hydroxy group of GalNAc residues in CS chains (Figure 3; Fukuta et al., 1998). Homozygous mutations in CHST3 cause spondyloepiphyseal dysplasia with congenital joint dislocations, which is characterized by a short stature, severe kyphoscoliosis, mild brachydactyly, arthritic joints, joint dislocation, rhizomelia, fusion of the carpal bones, metacarpal shortening, osteoarthritis of the elbow, deafness, and ventricular septal, mitral, and/or tricuspid defects (Table 2; Rajab et al., 2004; Thiele et al., 2004; van Roij et al., 2008; Tuysuz et al., 2009; Tanteles et al., 2013; Muys et al., 2016; Waryah et al., 2016; Srivastava et al., 2017). Loss of C6ST activity as well as the decrease of 6-O-sulfated CS were demonstrated in skin fibroblasts from patients (Thiele et al., 2004; van Roij et al., 2008). These findings suggest that chondroitin 4-O-sulfotransferase (C4ST) and/or 4-O-sulfation of CS cannot compensate for the loss-offunction in C6ST1.

Homozygous or heterozygous mutations in CHST3 cause Larsen syndrome and humero-spinal dysostosis, which are characterized by joint and knee dislocations, bilateral clubfeet, and elbow joint and spinal dysplasias (Table 2; Hermanns et al., 2008). Although there are a wide range of diagnoses for multiple dislocations in a newborn, Larsen syndrome is one of the most common entities (Hermanns et al., 2008). 
Hence, the different pathological diagnoses by mutations in CHST3 may be due to age-related descriptions of the same conditions (Hermanns et al., 2008). Twenty-four patients from 23 families with mutations in CHST3 were diagnosed with Larsen syndrome (15 families), humerospinal dysostosis (four cases), chondrodysplasia with multiple dislocations (Megarbane type; two cases), Desbuquois syndrome (one case), and spondyloepiphyseal dysplasia (one case) (Unger et al., 2010).

\section{Osteochondrodysplasia, Brachydactyly, and Overlapping Malformed Digits Caused by Mutations in CHST11}

CHST11 encodes chondroitin 4-O-sulfotransferase 1 (C4ST1), which transfers a sulfate group from PAPS to the C-4 hydroxy group of GalNAc residues in CS chains (Figure 3; Hiraoka et al., 2000; Yamauchi et al., 2000). Homozygous in-frame deletion of 15 nucleotides in CHST11, which results in the deletion of amino acids (Lys156-Asn160), causes limb malformations including brachydactyly, overriding digits, clino-symphalangism, syndactyly, and hexadactyly, and skeletal defects including scoliosis, dislocation of patellae and fibulae, and pectus excavatum (Table 2; Shabbir et al., 2018). Biochemical analyses using a recombinant enzyme as well as patients' cells have not been conducted to our knowledge.

The deletion of a 55-kb region within chromosome $12 \mathrm{q} 23$ that encompasses a part of CHST11 and an embedded microRNA, MIR3922, causes defects of the digits of the upper and lower limbs and malignant lymphoproliferative disease (Chopra et al., 2015). Although the digital malformations are consistent with the hallmarks of the proband who was homozygous for an in-frame deletion of 15 nucleotides in CHST11, as described above, the lymphoproliferative disorder is not. Hence, it remains unclear whether the deletion in CHST11 contributes to T-cell lymphoproliferative disorder. It should be noted that compound heterozygous variants in MBD3L5 and PRND and homozygous missense variants in EPHA10 and OLA1 were also identified in the proband (Chopra et al., 2015). Further analysis of CHST11 and/or 4-Osulfation of CS in the differentiation as well as proliferation of lymphocytes is required.

\section{CONGENITAL DISORDERS OF DERMATAN SULFATE DEFICIENCY}

\section{Ehlers-Danlos Syndrome Musculocontractural Type 2 Caused by Mutations in DSE}

DSE encodes dermatan sulfate epimerase (DSE), which converts GlcA into IdoA by epimerizing the C-5 carboxy group of GlcA residues in the repeating disaccharide region of the chondroitin precursor chain, [GlcA-GalNAc $]_{n}$, to form the disaccharide region of DS, [IdoA-GalNAc] ${ }_{n}$ (Figure 2A; Maccarana et al., 2006). The homozygous mutations in DSE cause EDS musculocontractural type 2 (Table 2; Müller et al., 2013; Syx et al., 2015; Lautrup et al., 2020; Malfait et al., 2020). The clinical hallmarks of the patients exhibited characteristic facial features including hypertelorism, blue sclera, midfacial hypoplasia, contracture of the thumbs and feet, atrophic scars on the skin, and hypermobility of the finger, elbow, and knee joints (Müller et al., 2013; Syx et al., 2015). DSE activity of the fibroblasts from the patient was markedly decreased compared with healthy control cells, which resulted in a lower level of DS, being accompanied by an increase in the level of CS (Müller et al., 2013). These findings indicate that mutations in DSE may cause a decrease in DS, leading to EDS musculocontractural type 2. In order to elucidate the underlying pathogenic mechanism of EDS, it will be necessary to analyze the signaling pathway(s) regulated by DS as well as functional protein(s) interacting with DS chains of DS-PGs.

\section{Bipolar Disorder and Diaphragmatic Hernia Caused by Mutations in DSEL}

DSEL encodes dermatan sulfate epimerase-like (DSEL)/DSE2, which is a homolog of DSE and can catalyze the reaction converting GlcA into IdoA (Pacheco et al., 2009). The 113 probands with bipolar disorder characterized by alternating episodes of depression were identified as caused by various homozygous as well as heterozygous mutations in DSEL, such as the substitution of adenine to guanine in the $5^{\prime}$-non-coding region 546 bp upstream of the coding region, p.Val287Ile, p.Pro673Ser, p.Tyr730Cys, p.Pro942Ser, and p.Ile1113Met, in DSEL (Table 2; Goossens et al., 2003). Moreover, the recurrent early-onset major depressive disorder was caused by single nucleotide polymorphism (SNP), rs17077540, which was detected $75 \mathrm{kbp}$ upstream of DSEL (Shi et al., 2011). DSEL but not DSE was demonstrated to be expressed predominantly in the brain (Table 2; Nakao et al., 2000; Maccarana et al., 2006; Akatsu et al., 2011; Bartolini et al., 2012). Functional analyses of DSEL using neuronal cells and model organisms such as the mouse and zebrafish, may lead to elucidation of the pathogenic mechanism of this disorder.

The deletion of $2.7 \mathrm{Mbp}$ at chromosome 18q22.1, which contains three genes, CDH19, DSEL, and TXNDC10/TMX3 encoding cadherin 19, DSEL/DSE2, and thioredoxin domaincontaining protein10/thioredoxin related transmembrane protein 3, respectively, causes diaphragmatic hernia (Zayed et al., 2010). Furthermore, the heterozygous substitution, c.1515G > A (p.Met14Ile), in DSEL also results in the disease (Table 2; Zayed et al., 2010). Thus, DSEL and/or DS might contribute to the development of the diaphragm, although the possibility of the involvement of CDH19 and TXNDC10/TMX3 in this disorder cannot be excluded.

\section{Ehlers-Danlos Syndrome Musculocontractural Type 1 Caused by Mutations in CHST14}

CHST14 encodes dermatan 4-O-sulfotransferase 1 (D4ST1), which transfers a sulfate group from PAPS to the C-4 hydroxy group of GalNAc residues in DS chains (Figure 3; 
Evers et al., 2001; Mikami et al., 2003). Homozygous, complex homozygous, or compound heterozygous mutations in CHST14 cause EDS musculocontractural type 1 (Table 2; Dündar et al., 2009; Malfait et al., 2010, 2020; Miyake et al., 2010), which is characterized by kyphoscoliosis, muscular hypotonia, hyperextensible, thin, and bruisable skin, atrophic scarring, joint hypermobility, multiple joint contracture, characteristic craniofacial features, joint laxities, and recurrent dislocations (Kosho et al., 2005, 2010; Dündar et al., 2009; Malfait et al., 2010, 2020; Miyake et al., 2010). Fibroblasts from probands with the mutations in CHST14 showed markedly lower D4ST activity than that from the respective control (Miyake et al., 2010). Surprisingly, CS, instead of non-sulfated DS (dermatan), was produced on the decorin core protein from skin fibroblasts of probands (Miyake et al., 2010). Collagen fibrils were dispersed in the patient dermis; in contrast, they were regularly and tightly assembled in the healthy controls (Hirose et al., 2019). The affected GAG side chain on decorin was altered from DS to CS. Since CS has a linear conformation, the CS side chain on decorin stretched from the outer surface of collagen fibrils to adjacent fibrils (Hirose et al., 2019). In contrast, DS has a curved conformation, and the DS side chain on decorin maintained close contact with attached collagen fibrils. Therefore, alteration of the side chain on decorin from DS to CS caused by loss-of-function in CHST11 results in the spatial disorganization of collagen networks, which may disrupt the appropriate structure of GAG side chains surrounding collagen fibrils (Hirose et al., 2019). Functional analyses of CHST14 using knockout mice are ongoing (Yoshizawa et al., 2018; Hirose et al., 2021; Nitahara-Kasahara et al., submitted).

Homozygous mutations or compound heterozygous mutation in CHST14 caused adducted thumb-clubfoot syndrome in 11 patients from 4 families (Table 2; Dündar et al., 2009). This syndrome is characterized by congenital contracture of the thumbs and feet, joint instability, a typical facial appearance, facial clefting, coagulopathy, thin and translucent skin, connective tissue fragility with aging, and defects in the heart, kidneys, or intestines (Dundar et al., 1997; Sonoda and Kouno, 2000; Janecke et al., 2001). Five out of eleven probands with adducted thumb-clubfoot syndrome died in early infancy or childhood (Dundar et al., 1997). Malfait et al. (2010) proposed to unify EDS and the adducted thumb-clubfoot syndrome, caused by mutations in CHST14, as "musculocontractural EDS," which was adopted in the 2017 International Classification of the Ehlers-Danlos syndromes as "EDS musculocontractural type 1" (Table 2; Malfait et al., 2017).

\section{CONGENITAL DISORDERS OF HEPARAN SULFATE DEFICIENCY}

\section{Multiple Osteochondromas Caused by EXT1 or EXT2 Mutations}

EXT1 encodes exostosin 1 (EXT1), a dual glycosyltransferase (GlcNAcT-II and HS-GlcAT-II), which transfers the GlcNAc and GlcA residues from UDP-GlcNAc and UDP-GlcA, respectively, to [GlcA-GlcNAc] ${ }_{n}$ (Figure 2A; Lind et al., 1998; McCormick et al., 1998). EXT2 also encodes a dual glycosyltransferase, which has activities of both GlcNAcT-II and HS-GlcAT-II (Lind et al., 1998; McCormick et al., 1998). The hetero-dimeric complex of EXT1 and EXT2 shows polymerization activity to construct repeating disaccharides in $\mathrm{HS}$, [GlcA-GlcNAc] ${ }_{n}$, by alternating addition of GlcA and GlcNAc from UDP-GlcA and UDPGlcNAc, respectively, in vitro (Figure 2A; Kim et al., 2003). Heterozygous mutations in EXT1 or EXT2 cause autosomal dominant disorder, osteochondroma, which is characterized by cartilaginous capped bony outgrowths located at the growth plates of long bones, a short stature, camptomelic dysplasia including the forearm and crus, early-onset osteoarthritis, and malignant transformation in approximately $1 \%$ of patients (Table 3; Solomon, 1963; Hennekam, 1991; Ahn et al., 1995; Stickens et al., 1996; Philippe et al., 1997; Wuyts et al., 1998; Bovée et al., 1999; Wuyts and Van Hul, 2000; Cheung et al., 2001; FaiyazUl-Haque et al., 2004). To our knowledge, 436 and 223 mutations in EXT1 and EXT2, respectively, have been identified to date.

Langer-Giedion syndrome (trichorhinophalangeal syndrome type II) is an autosomal dominant disorder caused by a deletion in chromosome 8q23.3-q24.11, which includes EXT1 and TRPS1 encoding exostosin 1 and transcriptional repressor GATA binding 1, respectively (Table 3; Lüdecke et al., 1995). Langer-Giedion syndrome is characterized by multiple osteochondromas, cone-shaped epiphyses, a short stature, bulbous nose, sparse scalp hair, a long philtrum, and bushy eyebrows (Lüdecke et al., 1995). A deletion in chromosome 8q24.11 or 8q23.3-q24.13, which contains EXT1, but not TRPS1, also causes Langer-Giedion syndrome (Wuyts et al., 2002; McBrien et al., 2008; Pereza et al., 2012).

A heterozygous deletion of $2.3 \mathrm{Mbp}$ in chromosome 11 p11.21 containing EXT2 causes Potocki-Shaffer-syndrome that is characterized by multiple osteochondromas, developmental delays, biparietal foramina, craniofacial abnormalities, and intellectual disability (Table 3; Swarr et al., 2010; Palka et al., 2012). These hallmarks, except for multiple osteochondromas, may be caused by the lack of eight other genes in the chromosome 11p11.21.

\section{Seizures-Scoliosis-Macrocephaly Syndrome Caused by Mutations in EXT2}

The complex homozygous mutations in EXT2 cause seizures-scoliosis-macrocephaly syndrome, but not multiple osteochondromas (Table 3; Farhan et al., 2015). The seizuresscoliosis-macrocephaly syndrome is characterized by seizures, intellectual disability, hypotonia, scoliosis, macrocephaly, hypertelorism, and renal dysfunction (Farhan et al., 2015). The protein level of the mutant EXT2, p.Met87Arg/p.Arg95Cys, in fibroblasts from patients was lower than that from control fibroblasts (Farhan et al., 2015). These findings indicate that EXT2 and/or HS side chains of HS-PGs may contribute to normal brain development, possibly by regulating the signaling pathway of Wnt as well as fibroblast growth factor (FGF) and/or by controlling the assembly of extracellular matrix. Wnt and FGF signalings were shown to 
be affected during nervous system development in zebrafish by mutants in ext2/dackel (Lee et al., 2004; Fischer et al., 2011).

\section{Immunoskeletal Dysplasia With Neurodevelopmental Abnormalities Caused by Mutations in EXTL3}

EXTL3 encodes exostosin-like-3 (EXTL3), a dual glycosyltransferase (GlcNAcT-I and GlcNAcT-II), which transfers a GlcNAc residue from UDP-GlcNAc to the GlcA residue at the non-reducing end of the common GAG-linker region tetrasaccharide and to the GlcA residue in the repeating disaccharide region of HS chains, respectively (Figure 2A; Kim et al., 2001). The homozygous mutations in EXTL3 cause immunoskeletal dysplasia with neurodevelopmental abnormalities that is characterized by severe platyspondyly, kyphoscoliosis, pelvic distortion, constriction of the proximal femora and brachydactyly, neurological abnormalities including generalized seizures, opisthotonus, hyperreflexia, intellectual disability, nystagmus, muscular hypotonia, and a decrease in T-lymphocyte subsets as well as immunoglobulins (Table 3; Guo et al., 2017b; Oud et al., 2017; Volpi et al., 2017). Although wild-type EXTL3 from a healthy subject localized to the Golgi apparatus, p.Arg513Cys-EXTL3 from a patient did not (Oud et al., 2017). Therefore, the mislocalization of the mutant EXTL3 (p.Arg513Cys) may cause loss-of-function of EXTL3. Moreover, HS levels in the fibroblasts of patients were markedly lower than those in healthy controls (Oud et al., 2017). Up-regulation of FGF signaling as well as increase in the 2-O- and 6-O-sulfation of HS were observed in the fibroblasts of a patient with a homozygous mutation in EXTL3 (Volpi et al., 2017), being consistent with the reports that FGF signaling requires both 2-O- and 6-O-sulfation on HS. The reduced expansion of lymphohematopoietic progenitor cells and defects in the differentiation of thymic epithelial progenitor cells were also detected in the induced pluripotent stem (iPS) cells of the patient (Volpi et al., 2017). These findings suggest that EXTL3 and/or HS-PGs play roles in not only skeletal development, but also cell differentiation of the nervous and immune systems. Their functions in specific organs such as the brain and thymus are under investigation using conditional knockout mice.

\section{Intellectual Disability Due to Autosomal Recessive State Caused by Mutations in NDST1}

NDST1 encodes GlcNAc $N$-deacetylase/ $N$-sulfotransferase 1 (NDST1), which has bifunctional domains including an $\mathrm{N}$-deacetylase and $\mathrm{N}$-sulfotransferase, acting on GlcNAc residues in HS chains (Figure 3; Hashimoto et al., 1992; Dixon et al., 1995). The homozygous mutations in NDST1 cause autosomal recessive intellectual disability, muscular hypotonia, epilepsy, and postnatal growth deficiency (Table 3; Najmabadi et al., 2011; Reuter et al., 2014). Furthermore, the compound heterozygous mutation in NDST1 causes developmental delay, a short stature, seizures, cranial nerve palsies, ataxia, severe respiratory difficulties in infancy, and distinctive facial features including a long nose and bifid uvula (Table 3; Armstrong et al., 2017). These findings suggest that NDST1 and/or N-sulfation in HS chains may contribute to development of the brain and lungs and maintenance of their functions.

\section{Neurofacioskeletal Syndrome With or Without Renal Agenesis Caused by Mutations in HS2ST1}

HS2ST1 encodes HS 2-O-sulfotransferase 1 (HS2ST1), which transfers a sulfate group from PAPS to the C-2 hydroxy group of GlcA as well as IdoA residues in HS chains (Figure 3; Kobayashi et al., 1997). Complex heterozygous mutations in HS2ST1 cause the brachydactyly of hands and feet, flexion contractures, corpus callosum agenesis or hypoplasia, intellectual disability, uni- or bilateral renal agenesis, developmental delay, and facial dysmorphism such as a coarse face, upslanted palpebral fissures, a broad nasal tip, and wide mouth (Table 3; Schneeberger et al., 2020). HS chains of skin fibroblasts from patients lacked 2-O-sulfation of GlcA/IdoA residues, resulting in an increase in $\mathrm{N}$ - and 6-O-sulfation of glucosamine residue (Schneeberger et al., 2020). Furthermore, decreased activation of mitogen-activated protein kinase, ERK1/2, by FGF2, was detected in the cell cultures of affected individuals (Schneeberger et al., 2020). These findings indicate that HS2ST1 and 2-O-sulfated HS are required for skeletal and renal development in humans.

\section{Hypogonadotropic Hypogonadism With or Without Anosmia and Kallmann Syndrome Caused by Mutations in HS6ST1}

HS6ST1 encodes HS 6-O-sulfotransferase 1 (HS6ST1), which transfers a sulfate group from PAPS to the C- 6 hydroxy group of GlcNAc and glucosamine residues in HS chains (Figure 3; Habuchi et al., 1998, 2000). The homozygous or heterozygous mutations cause Kallmann syndrome and idiopathic hypogonadotrophic hypogonadism (Table 3; Tornberg et al., 2011). Congenital hypogonadotrophic hypogonadism is characterized by the impaired production or action of gonadotropin-releasing hormone $(\mathrm{GnRH})$, which results in dysfunction of the hypothalamic-pituitary-gonadal hormone axis, leading to low testosterone levels and impaired fertility (Boehm et al., 2015; Millar et al., 2021). Furthermore, congenital hypogonadotrophic hypogonadism is a GnRH deficiency that is associated with other developmental anomalies including a cleft lip or palate, dental agenesis, ear anomalies, hearing impairment, renal agenesis, bimanual synkinesis, and skeletal anomalies (Boehm et al., 2015). Kallmann syndrome is characterized by anosmia or hyposmia in addition to the manifestations of hypogonadotrophic hypogonadism, which results from abnormal embryonic migration of GnRH neurons from their origin in the olfactory placode to the forebrain (Boehm et al., 2015). Congenital hypogonadotrophic hypogonadism and Kallmann syndrome are caused by mutations 
in KAL1/ANOS1, FGF8, FGF17, and FGF receptor 1 (FGFR1) (Bick et al., 1992; Dodé et al., 2003; Falardeau et al., 2008; Miraoui et al., 2013). Anosmin-1, an extracellular matrix protein, encoded by KAL1/ANOS1 enhances FGF signaling through interaction with the FGF-FGFR-HS-PG complex on the cell surface (González-Martínez et al., 2004). These findings suggest that 6-O-sulfation of GlcNAc and/or glucosamine residues in HS chains is required for their interaction with anosmin-1 and/or FGF, thereby allowing the regulation of FGF signaling.

\section{CONGENITAL DISORDERS OF KERATAN SULFATE DEFICIENCY}

\section{Macular Corneal Dystrophy Caused by Mutations in CHST6}

CHST6 encodes a corneal GlcNAc 6-O-sulfotransferase (CGlcNAc6ST), which transfers a sulfate group from PAPS to the C-6 hydroxy group of GlcNAc in KS chains (Figure 3; Akama et al., 2001, 2002). Homozygous, heterozygous, or compound heterozygous mutations in CHST6 cause macular corneal dystrophy characterized by an autosomal recessive hereditary disease, progressive punctate opacities in the cornea, bilateral loss of vision (Table 4; Akama et al., 2000; El-Ashry et al., 2002; Aldave et al., 2004; Sultana et al., 2005). However, the influence of a defect in CHST6 on KS biosynthesis remains unclear. Hence, further analyses of the sulfated modification as well as level of KS are required to elucidate the underlying pathogenic mechanisms.

\section{CONGENITAL DISORDERS CAUSED BY DEFICIENCY OF URIDINE DIPHOSPHATE-GLUCURONIC ACID AND 3'-PHOSPHOADENOSINE 5'-PHOSPHOSULFATE SYNTHASE}

\section{Developmental and Epileptic Encephalopathy Caused by Mutations in UGDH}

$U G D H$ encodes UDP-Glc dehydrogenase (UGDH), which is an oxidoreductase that converts UDP-Glc to UDP-GlcA in the cytosol (Figure 1; Spicer et al., 1998). Compound heterozygous and homozygous mutations in $U G D H$ cause developmental and epileptic encephalopathy, characterized by intractable epileptic seizures and developmental delay (Table 5; Freeze et al., 2015; McTague et al., 2016; Hengel et al., 2020). The recombinant mutant enzyme of UGDH, p.Ala44Val and p.Ala82Thr, mainly forms a dimer or remains a monomer species, respectively, whereas the wild-type UGDH predominantly forms a hexamer (Hengel et al., 2020). Furthermore, the values of $V_{\max }$ of p.Ala44Val and p.Ala82Thr enzymes were less than 50\% and at an undetermined level, respectively, compared with that of the wild-type (Hengel et al., 2020). The probands of
36 cases from 25 families showed epileptic encephalopathy with developmental delay and hypotonia (Hengel et al., 2020). These hallmarks are similar to those probands with mutations in CHSY1, EXTL3, or NDST1 (Li et al., 2010; Tian et al., 2010; Najmabadi et al., 2011; Reuter et al., 2014; Guo et al., 2017b; Oud et al., 2017; Volpi et al., 2017). Thus, UGDH and/or UDP-GlcA is responsible for not only neuronal development but also the biosynthesis of GAGs. Although the level of GAGs in patients with mutations in $U G D H$ has not been investigated, the embryos from mutant mice, lazy mesoderm, with mutations in UGDH showed less staining with anti-CS or anti-HS antibodies, compared with the wild-type embryos for both antibodies (García-García and Anderson, 2003). Further analyses including quantification of GAGs from patients and glucuronokinase as well as UDP-GlcA pyrophosphrylase that form GlcA-1-phosphate and UDP-GlcA, respectively, which have been identified in zebrafish but not mammals, are required.

\section{Spondyloepimetaphyseal Dysplasia of the Pakistani Type and Brachyolmia 4 With Mild Epiphyseal and Metaphyseal Changes Caused by Mutations in PAPSS2}

PAPSS2 encodes PAPS synthase 2 (PAPSS2), which is a dual enzyme containing ATP sulfurylase and adenosine $5^{\prime}$-phosphosulfate kinase domains at $\mathrm{C}$ - and $\mathrm{N}$-terminals, respectively (Figure 1; Fuda et al., 2002; Venkatachalam, 2003). Spondyloepimetaphyseal dysplasia of the Pakistani type that is characterized by a short stature at birth, shortbowed lower limbs, mild brachydactyly, kyphoscoliosis, enlarged knee joints, and early-onset degenerative joint disease of the hands and knees, is caused by homozygous mutations in PAPSS2 (Table 5; Ahmad et al., 1998; Tüysüz et al., 2013).

Compound heterozygous mutations in PAPSS2 cause hyperandrogenism, premature pubarche, and hyperandrogenic anovulation, in addition to a short stature and skeletal dysplasia, which may result from a low level of serum dehydroepiandrosterone sulfate with increasing androgen

(Table 5; Noordam et al., 2009).

Furthermore, brachyolmia, which is characterized by a short stature, short trunk, irregular endplates, narrow intervertebral disks, precocious calcification of rib cartilages, a short femoral neck, mildly shortened metacarpals, and a normal intelligence and facies, are also caused by compound heterozygous and homozygous mutations in PAPSS2 (Table 5; Miyake et al., 2012; Iida et al., 2013; Bownass et al., 2019). PAPSS2 mutation might present a gradation of the phenotypic spectrum from brachyolmia to spondylo-epiphyseal and spondylo-epimetaphyseal dysplasia of the Pakistani type (Miyake et al., 2012). Brachymorphic mice, which have a missense mutation, p.Gly79Arg, in PAPSS2, are characterized by short stature as well as low level of CS (Sugahara and Schwartz, 1979; Pennypacker et al., 1981; Kurima et al., 1998). These 
TABLE 5 | Congenital disorders of UDP-sugars, PAPS, and related protein deficiencies*.

\begin{tabular}{|c|c|c|c|c|c|}
\hline Gene & Protein & $\begin{array}{l}\text { Chromosomal } \\
\text { location }\end{array}$ & MIM number & Name of disorder & Clinical hallmarks \\
\hline$U G D H$ & $\begin{array}{l}\text { UDP-Glc } \\
\text { dehydrogenase }\end{array}$ & & $\begin{array}{l}603370 \\
618792\end{array}$ & $\begin{array}{l}\text { Developmental and epileptic } \\
\text { encephalopathy } 84\end{array}$ & $\begin{array}{l}\text { Intractable epileptic seizures and } \\
\text { developmental delay. }\end{array}$ \\
\hline PAPSS2 & PAPS synthase 2 & 10q23.2-q23.3 & $\begin{array}{l}612847 \\
603005\end{array}$ & $\begin{array}{l}\text { Brachyolmia } 4 \text { with mild epiphyseal } \\
\text { and metaphyseal changes; } \\
\text { Spondyloepimetaphyseal dysplasia } \\
\text { Pakistani type (PAPSS2 type); } \\
\text { Hyperandrogenism }\end{array}$ & $\begin{array}{l}\text { Short, bowed lower limbs, enlarged knee joints, } \\
\text { kyphoscoliosis, and mild generalized } \\
\text { brachydactyly, androgen excess, premature } \\
\text { pubarche, hyperandrogenic anovulation, } \\
\text { dehydroepiandrosterone, a short trunk. }\end{array}$ \\
\hline SLC26A2 & $\begin{array}{l}\text { Diastrophic } \\
\text { dysplasia sulfate } \\
\text { transporter } \\
\text { (DTDST) }\end{array}$ & $5 q 32$ & $\begin{array}{l}600972 \\
256050 \\
222600 \\
226900 \\
606718\end{array}$ & $\begin{array}{l}\text { Achondrogenesis type IB; } \\
\text { Atelosteogenesis type II; De la } \\
\text { Chapelle dysplasia; Diastrophic } \\
\text { dysplasia; Diastrophic dysplasia, } \\
\text { broad bone-platyspondylic variant; } \\
\text { Epiphyseal dysplasia multiple } 4\end{array}$ & $\begin{array}{l}\text { Lethal chondrodysplasia with severe } \\
\text { under-development of the skeleton, extreme } \\
\text { micromelia, death before or immediately after } \\
\text { birth, epiphyseal dysplasia and early-onset } \\
\text { osteoarthritis. }\end{array}$ \\
\hline SLC35A3 & $\begin{array}{l}\text { UDP-GlcNAc } \\
\text { transporter }\end{array}$ & 1p21.2 & $\begin{array}{l}605632 \\
615553\end{array}$ & $\begin{array}{l}\text { Arthrogryposis, intellectual disability, } \\
\text { and seizures }\end{array}$ & $\begin{array}{l}\text { Arthrogryposis, knee and hip dislocations, } \\
\text { anomalous vertebrae, hypotonia, autism, } \\
\text { epilepsy, seizure, and mild to moderate } \\
\text { intellectual disability. }\end{array}$ \\
\hline SLC35D1 & $\begin{array}{l}\text { UDP-GlcA/UDP- } \\
\text { GalNAc dual } \\
\text { transporter }\end{array}$ & $1 \mathrm{p} 31.3$ & $\begin{array}{l}610804 \\
269250\end{array}$ & Schneckenbecken dysplasia & $\begin{array}{l}\text { Neonatal lethal chondrodysplasia, } \\
\text { platyspondyly with oval-shaped vertebral } \\
\text { bodies, extremely short long bones with a } \\
\text { dumbbell-like appearance, and small ilia with a } \\
\text { snail-like appearance. }\end{array}$ \\
\hline \multirow[t]{2}{*}{ CANT1 } & $\begin{array}{l}\text { UDP } \\
\text { diphosphatase }\end{array}$ & $17 q 25.3$ & $\begin{array}{l}617719 \\
251450 \\
613165\end{array}$ & $\begin{array}{l}\text { Desbuquois dysplasia 1; } \\
\text { Epiphyseal dysplasia multiple } 7\end{array}$ & $\begin{array}{l}\text { A short stature, joint laxity, scoliosis, and } \\
\text { advanced carpal ossification with a delta } \\
\text { phalanx. }\end{array}$ \\
\hline & & & 264180 & Pseudodiastrophic dysplasia & See disorder of BЗGAT3 in Table 1. \\
\hline IMPAD1 & $\begin{array}{l}3^{\prime} \text { - } \\
\text { Phosphoadenosine } \\
5^{\prime} \text {-phosphate } \\
\text { 3'-phosphatase }\end{array}$ & $8 q 12.1$ & $\begin{array}{l}614078 \\
614010\end{array}$ & $\begin{array}{l}\text { Chondrodysplasia with joint } \\
\text { dislocations GRAPP type }\end{array}$ & $\begin{array}{l}\text { A short stature, chondrodysplasia, with } \\
\text { brachydactyly, congenital joint dislocations, a } \\
\text { cleft palate, and facial dysmorphism. }\end{array}$ \\
\hline GORAB & $\begin{array}{l}\text { Golgin, } \\
\text { Rab6-interacting } \\
\text { protein }\end{array}$ & $1 \mathrm{q} 24.2$ & $\begin{array}{l}607983 \\
231070\end{array}$ & Geroderma osteodysplasticum & $\begin{array}{l}\text { Lax and wrinkled skin, joint laxity, a typical face } \\
\text { with a prematurely aged appearance, severe } \\
\text { osteoporosis, malar and mandibular hypoplasia, } \\
\text { and a variable degree of growth retardation. }\end{array}$ \\
\hline COG4 & $\begin{array}{l}\text { Component of } \\
\text { oligomeric Golgi } \\
\text { complex } 4\end{array}$ & $16 q 22.1$ & $\begin{array}{l}606976 \\
618150\end{array}$ & Saul-Wilson syndrome & $\begin{array}{l}\text { A short stature, prominent forehead, prominent } \\
\text { eyes, narrow nasal bridge, micrognathia, } \\
\text { clubfoot, brachydactyly, short distal phalanges } \\
\text { of fingers, irregular end plates of vertebral } \\
\text { bodies, hypoplasia of the odontoid process, } \\
\text { and metaphyseal flaring in the long bones. }\end{array}$ \\
\hline
\end{tabular}

*, the table was cited from a reference (Mizumoto, 2018) with modifications.

SLC, solute carrier family; CANT1, calcium-activated nucleotidase; IMPAD1, inositol monophosphatase domain-containing protein 1.

findings indicate that sulfated modification of CS is required for cartilage development.

\section{CONGENITAL DISORDERS BY DEFICIENCY OF URIDINE DIPHOSPHATE-SUGAR AND SULFATE TRANSPORTERS}

\section{Diastrophic Dysplasia and Achondrogenesis Type IB Caused by Mutations in SLC26A2}

SLC26A2 encodes a sulfate transporter, which incorporates sulfate anions into the cytosol at the plasma membrane
(Figure 1; Hästbacka et al., 1994; Satoh et al., 1998; Seidler and Nikolovska, 2019). The incorporated sulfate is activated to adenosine-phosphosulfate and then to PAPS by PAPS synthase (Venkatachalam, 2003). Mutations in SLC26A2 cause diastrophic dysplasia, achondrogenesis $1 \mathrm{~B}$, and atelosteogenesis type 2 (Table 5; Hästbacka et al., 1994, 1996; Superti-Furga et al., 1996; Rossi and Superti-Furga, 2001). Diastrophic dysplasia is an osteochondrodysplasia characterized by a short-limbed short stature, kyphoscoliosis, generalized dysplasia of the joints, hitchhiker thumbs, metatarsus adductus deformity of the feet, deformation of the ear lobes, and cleft plate (Superti-Furga et al., 1996). Achondrogenesis 1B is also a recessively inherited chondrodysplasia, which is characterized by extremely poor skeletal development and perinatal death (Table 5; SupertiFurga et al., 1996). Furthermore, atelosteogenesis type 2 is 
characterized by severely shortened limbs, a small chest, scoliosis, a club foot, abducted thumbs and great toes, and cleft palate (Table 5; Hästbacka et al., 1996). The incorporation of sulfate and formation of adenosine-phosphosulfate as well as PAPS were impaired in cultured cells from the proband of achondrogenesis $1 \mathrm{~B}$, thereby resulting in the sulfation of PGs (Superti-Furga et al., 1996). These findings suggest that mutations in SLC26A2 cause low sulfation of GAGs, thereby disturbing the assembly of the extracellular matrix as well as cellular signaling.

\section{Arthrogryposis, Intellectual Disability, and Seizures Caused by Mutations in SLC35A3}

SLC35A3 encodes UDP-GlcNAc transporter, which incorporates UDP-GlcNAc into the Golgi apparatus from the cytosol (Figure 1; Ishida et al., 1999; Szulc et al., 2020). Compound heterozygous and homozygous mutations of SLC35A31 cause neuroskeletal disorder, which is characterized by arthrogryposis, knee and hip dislocations, anomalous vertebrae, hypotonia, autism, epilepsy, seizure, and mild to moderate intellectual disability (Table 5; Edvardson et al., 2013; Edmondson et al., 2017; Miyake et al., 2021). Moreover, the probands showed deficiency of several N-glycans, no difference in the biosynthesis of keratan sulfate, and hallmarks such as cleft palate, micrognathia, a patent foramen ovale, patent ductus arteriosus, posterior embryotoxon, short limbs, camptodactyly, talipes valgus, rocker-bottom feet, and facial dysmorphism (Edvardson et al., 2013; Edmondson et al., 2017). Notably, a CS side chain of serum bikunin, CS-PG, from a patient with mutation in SLC35A3 was shorter than that from a control subject (Haouari et al., 2020). Because CS did not contain the GlcNAc residue, the finding indicates several possibilities that SLC35A3 transports UDP-GalNAc in addition to UDP-GlcNAc, and that UDPGlcNAc- $4^{\prime}$-epimerase/UDP-Gal-4'-epimerase encoded by GALE is located in the Golgi apparatus in addition to cytosol (Thoden et al., 2001; Broussard et al., 2020; Fushinobu, 2021).

\section{Schneckenbecken Dysplasia Caused by Mutations in SLC35D1}

SLC35D1 encodes UDP-GlcA/UDP-GalNAc dual transporter, which incorporates UDP-GlcA and UDP-GalNAc into the Golgi apparatus from the cytosol (Figure 1; Muraoka et al., 2001). Mutations of SLC35D1 cause Schneckenbecken dysplasia, which is characterized by perinatally lethal skeletal dysplasia, thoracic hypoplasia, severe flattening of the vertebral bodies and short, thick long bones (Table 5; Hiraoka et al., 2007; Furuichi et al., 2009). The German term "Schneckenbecken" refers to the snail-like appearance of the ilia that results from a medial bone projection from the inner iliac margin (Nikkels et al., 2001). Mice deficient in Slc35d1 $1^{-/-}$showed decreased CS in the cartilage and no change in HS (Hiraoka et al., 2007). These findings suggest that SLC35D1 predominantly transports UDP-GalNAc rather than UDP-GlcA in vitro to form CS polysaccharides in the Golgi apparatus.

\section{CONGENITAL DISORDERS CAUSED BY GLYCOSAMINOGLYCAN-RELATED GENES}

\section{Desbuquois Dysplasia 1 Caused by Mutations in CANT1}

CANT1 encodes a calcium-dependent nucleoside diphosphatase that hydrolyzes UDP, which is a reaction product after transfer of a sugar residue by a glycosyltransferase, into uridine $5^{\prime}$ monophosphate (UMP) and an inorganic phosphate in the Golgi apparatus (Figure 1; Failer et al., 2002; Smith et al., 2002). The compound heterozygous and homozygous mutations cause Desbuquois dysplasia type 1, which is characterized by severe growth retardation, joint laxity, short extremities, and progressing scoliosis (Table 5; Huber et al., 2009; Faden et al., 2010; Dai et al., 2011; Furuichi et al., 2011; Laccone et al., 2011; Nizon et al., 2012b; Singh et al., 2015; Balasubramanian et al., 2017; Menzies et al., 2019). The phenotypes of this disorder are common to those of Desbuquois dysplasia type 2 caused by mutations in XYLT1 (Bui et al., 2014; Silveira et al., 2016; Al-Jezawi et al., 2017; Guo et al., 2017a).

Homozygous mutation in CANT1 causes pseudodiastrophic dysplasia, which is associated with prenatal manifestation and early lethality (Table 5; Byrne et al., 2020). The probands showed similar hallmarks with the probands with a compound heterozygous mutation in B3GAT3 (Byrne et al., 2020).

These findings suggest that the accumulation of UDP in the Golgi apparatus might inhibit the enzyme activity of XYLT1, B3GAT3 and UDP-GlcA decarboxylase/UDP-Xyl synthase, and the decrease in UMP might lead to impairment of UDP-Xyl or UDP-GlcA transporters, which are antiporters for UMP and UDP-XYl or UDP-GlcA, respectively, thereby resulting in defects in the biosynthesis of GAGs.

\section{Chondrodysplasia With Joint Dislocations of GPAPP Type Caused by Mutations in IMPAD1}

The sulfate donor substrate, PAPS, is converted into adenosine$3^{\prime}, 5^{\prime}$-bisphosphate after a reaction with a sulfotransferase in the Golgi apparatus. IMPAD1 encodes inositol monophosphatase domain-containing protein 1/Golgi $3^{\prime}$-phosphoadenosine $5^{\prime}$-phosphate $\quad 3^{\prime}$-phosphatase (IMPAD1/GPAPP), which hydrolyzes the phosphate from $3^{\prime}$-phosphoadenosine $5^{\prime}$-phosphate to adenosine $5^{\prime}$-phosphate (Figure 1; Vissers et al., 2011; Nizon et al., 2012a). Homozygous mutations in IMPAD1 cause chondrodysplasia with joint dislocations (Table 5; Vissers et al., 2011; Nizon et al., 2012a), which is characterized by a short stature, brachydactyly, joint dislocations, micrognathia, cleft palate, and facial dysmorphism (Vissers et al., 2011; Nizon et al., 2012a). The knockout mice, Impad1-/-, exhibited a reduction of 4-O-sulfated CS with increasing non-sulfated CS, and a small decrease in total sulfated HS with a corresponding 
increase of non-sulfated HS in the lung (Frederick et al., 2008). Therefore, the catabolic abnormality in the reaction product of donor substrate including $3^{\prime}$-phosphoadenosine $5^{\prime}$-phosphate may result in the inhibition of GAG-sulfotransferases, and such skeletal disorders develop.

\section{Geroderma Osteodysplasticum Caused by Mutations in GORAB}

$G O R A B$ encodes Rab6-interacting Golgi protein (Hennies et al., 2008; Takeda et al., 2017). The homozygous mutations in GORAB cause gerodermia osteodysplastica that is characterized by skin laxity and early-onset osteoporosis (Table 5; Rajab et al., 2008). The knockout mice, GORAB $B^{-/-}$, showed a reduction in the level of DS, but not CS and HS, in skin and cartilage (Chan et al., 2018). These findings suggest that the loss of Gorab results in a defect of the DS side chain in PGs due to disturbed transport in the Golgi compartment, leading to the development of gerodermia osteodysplastica.

\section{Saul-Wilson Syndrome Caused by Mutations in COG4}

COG4 encodes the component of oligomeric Golgi complex 4, which is involved in intracellular vesicular transport (Climer et al., 2018). The heterozygous mutation in COG4 causes a rare skeletal dysplasia, Saul-Wilson syndrome, which is characterized by a short stature, prominent forehead, prominent eyes, a narrow nasal bridge, micrognathia, clubfoot, brachydactyly, short distal phalanges of fingers, irregular end plates of vertebral bodies, hypoplasia of the odontoid process, and metaphyseal flaring in the long bones (Table 5; Saul and Wilson, 1990; Ferreira et al., 2018). Although protein $N$-glycosylation in sera and fibroblasts from probands was not notably altered, DS-PG, decorin, was affected. A smaller population of glycanated decorin and longer CS/DS side chain on decorin in the affected fibroblasts were observed, compared with those in healthy subjects (Ferreira et al., 2018). These findings suggest that specific transport by oligomeric Golgi complex might affect the cellular localization and/or polymerization as well as sulfation of specific PGs.

\section{CONGENITAL DISORDERS CAUSED BY MUTATIONS IN CORE PROTEINS OF PROTEOGLYCANS}

\section{Chondroitin Sulfate-Proteoglycans}

Aggrecan encoded by ACAN consists of a protein with 2,431 amino acids $(\sim 220 \mathrm{kDa})$, which is modified by CS $(>100$ chains per monomer), KS, and other oligosaccharides (Doege et al., 1991). The autosomal dominant spondyloepiphyseal dysplasia Kimberley type, which is characterized by short stature, stocky build, early-onset osteoarthritis of joints, flattened vertebral bodies with sclerosis and end-plate irregularity, and flattened femoral epiphyses, is caused by a single-base-pair insertion in ACAN, which introduces a frameshift of 212 amino acids, including 22 cysteine residues, followed by a premature stop codon (Table 6; Gleghorn et al., 2005). Furthermore, homozygous or heterozygous mutations in ACAN cause spondyloepimetaphyseal dysplasia Aggrecan type or dominant familial osteochondritis dissecans, respectively (Tompson et al., 2009; Stattin et al., 2010).

Versican encoded by VCAN consists of a protein with 3,396 amino acids, which has $\sim 20$ putative CS attachment sites as well as potential $\mathrm{N}$ - and $\mathrm{O}$-glycosylation sites (Dours-Zimmermann and Zimmermann, 1994). The autosomal dominant Wanger syndrome, which is characterized by vitreoretinopathy, an empty vitreous cavity, vitreous degeneration, progressive chorioretinal atrophy, perivascular sheathing, subcapsular cataract, and myopia, is caused by heterozygous mutations in VCAN (Table 6; Miyamoto et al., 2005; Kloeckener-Gruissem et al., 2006, 2013).

\section{Dermatan Sulfate-Proteoglycans}

Biglycan encoded by $B G N$ consists of a protein with 368 amino acids, which has 2 putative DS attachment sites (Fisher et al., 1989). Two missense mutations in BGN cause the $\mathrm{X}$-linked form of spondyloepimetaphyseal dysplasia, which is characterized by anomalies of the spine as well as the epiphyses and metaphyses of the long bones, thereby resulting in a short stature and osteoarthritic changes in joints (Table 6; Cho et al., 2016). Thoracic aortic aneurysms and dissections are also caused by missense and non-sense mutations and 21 or $28-\mathrm{kb}$ deletions in BGN (Meester et al., 2017). The clinical hallmarks are characterized by the early-onset of aortic aneurysm and dissection, joint hypermobility and contractures, deformities of the skin striae and pectus, craniofacial dysmorphisms including dolichocephaly, hypertelorism, down-slanting eyes, a higharched plate, proptosis, malar hypoplasia, and frontal bossing as well as manifestations of Loeys-Dietz syndrome such as a bifid uvula and cervical spine instability (Meester et al., 2017). Moreover, TGF $\beta$ signaling is up-regulated in patients, thereby being similar to probands with Loeys-Dietz syndrome caused by mutations in TGF $\beta$ signaling-related proteins (Van Laer et al., 2014).

Decorin encoded by DCN consists of a protein with 359 amino acids, which has a putative DS attachment site (Fisher et al., 1989). Autosomal dominant congenital stromal corneal dystrophy is caused by mutations in $D C N$, and is characterized by corneal clouding with fine opacities observed as small flakes and spots, refractive errors, amblyopia, strabismus, nystagmus, and esotropia (Table 6; Van Ginderdeuren et al., 2002; Bredrup et al., 2005; Rødahl et al., 2006; Kim et al., 2011; Jing et al., 2014). All mutations in DCN causing dominant corneal dystrophy result in the truncated forms of decorin core protein, which may affect matrix assembly in the corneal stroma in a dominantnegative manner, supported by analyses using model mice with a frameshift mutation in Dcn (Chen et al., 2011).

\section{Heparan Sulfate-Proteoglycans}

Glypicans encoded by GPC1 to GPC6 consist of proteins with 550-580 amino acids, which have two putative HS attachment sites at the C-terminus. Glypicans are bound to the plasma membrane by a glycosylphosphatidylinositol (GPI) anchor (Filmus et al., 2008; Filmus and Capurro, 2014). 
TABLE 6 | Congenital disorders of core proteins of PGs.

\begin{tabular}{|c|c|c|c|c|c|}
\hline Gene & Protein & $\begin{array}{l}\text { Chromosomal } \\
\text { location }\end{array}$ & MIM number & Name of disorder & Clinical hallmarks \\
\hline ACAN & Aggrecan & $15 q 26.1$ & $\begin{array}{l}155760 \\
608361 \\
165800 \\
612813\end{array}$ & $\begin{array}{l}\text { Spondyloepiphyseal dysplasia } \\
\text { Kimberley type; } \\
\text { Spondyloepimetaphyseal dysplasia, } \\
\text { aggrecan type; Short stature and } \\
\text { advanced bone age, with or without } \\
\text { early-onset osteoarthritis and/or } \\
\text { osteochondritis dissecans }\end{array}$ & $\begin{array}{l}\text { A short stature, stocky build, early-onset } \\
\text { osteoarthritis of joints, flattened vertebral } \\
\text { bodies with sclerosis and end-plate irregularity, } \\
\text { and flattened femoral epiphyses. }\end{array}$ \\
\hline VCAN & Versican & $5 q 14.2-q 14.3$ & $\begin{array}{l}118661 \\
143200\end{array}$ & Wanger syndrome & $\begin{array}{l}\text { Vitreoretinopathy, an empty vitreous cavity, } \\
\text { vitreous degeneration, progressive chorioretinal } \\
\text { atrophy, perivascular sheathing, subcapsular } \\
\text { cataract, and myopia. }\end{array}$ \\
\hline$B G N$ & Biglycan & Xq28 & $\begin{array}{l}301870 \\
300106 \\
300989\end{array}$ & $\begin{array}{l}\text { Spondyloepimetaphyseal dysplasia, } \\
\text { X-linked; Meester-Loeys syndrome }\end{array}$ & $\begin{array}{l}\text { Anomalies of spine and epiphyses, metaphyses } \\
\text { of long bones, a short stature, and } \\
\text { osteoarthritic changes in joints }\end{array}$ \\
\hline$D C N$ & Decorin & $12 q 21.33$ & $\begin{array}{l}125255 \\
610048\end{array}$ & Corneal dystrophy, congenital stromal & $\begin{array}{l}\text { Corneal clouding, refractive errors, amblyopia, } \\
\text { strabismus, nystagmus, and esotropia. }\end{array}$ \\
\hline GPC3 & Glypican 3 & Xq26.2 & $\begin{array}{l}300037 \\
312870\end{array}$ & $\begin{array}{l}\text { Simpson-Golabi-Behmel syndrome } \\
\text { type } 1\end{array}$ & $\begin{array}{l}\text { Pre- and postnatal overgrowth, visceral and } \\
\text { skeletal anormalies, a coarse face, heart } \\
\text { defects, and hypotonia. }\end{array}$ \\
\hline GPC4 & Glypican 4 & Xq26.2 & $\begin{array}{l}300168 \\
301026\end{array}$ & Keipert syndrome & $\begin{array}{l}\text { Craniofacial and digital abnormalities, variable } \\
\text { learning difficulties, and sensorineural deafness. }\end{array}$ \\
\hline GPC6 & Glypican 6 & 13q31.3-q32.1 & $\begin{array}{l}604404 \\
258315\end{array}$ & Omodysplasia 1 & $\begin{array}{l}\text { Proximally shortened limbs, facial } \\
\text { dysmorphism, a severely short stature, and } \\
\text { hypoplastic humeri. }\end{array}$ \\
\hline \multirow[t]{2}{*}{ HSPG2 } & Perlecan & $1 p 36.12$ & $\begin{array}{l}255800 \\
142461\end{array}$ & Schwartz-Jampel syndrome & $\begin{array}{l}\text { Permanent myotonia and skeletal dysplasia } \\
\text { including a short stature, kyphoscoliosis, } \\
\text { bowing of the diaphyses and irregular } \\
\text { epiphyses. }\end{array}$ \\
\hline & & & 224410 & $\begin{array}{l}\text { Dyssegmental dysplasia } \\
\text { Silverman-Handmaker type }\end{array}$ & $\begin{array}{l}\text { A flat face, micrognathia, cleft palate, reduced } \\
\text { joint mobility, and encephalocele. }\end{array}$ \\
\hline AGRN & Agrin & $1 \mathrm{p} 36.33$ & $\begin{array}{l}103320 \\
615120\end{array}$ & $\begin{array}{l}\text { Myasthenic syndrome, congenital, } 8 \text {, } \\
\text { with pre- and post-synaptic defects }\end{array}$ & $\begin{array}{l}\text { Changes in the nerve-terminal cytoskeleton and } \\
\text { fragmentation of the synaptic gutters, and } \\
\text { muscle weakness. }\end{array}$ \\
\hline COL18A1 & Collagen $18 \alpha 1$ & $21 \mathrm{q} 22.3$ & $\begin{array}{l}120328 \\
267750\end{array}$ & Knobloch syndrome type 1 & $\begin{array}{l}\text { High myopia, vitreoretinal degeneration with } \\
\text { retinal detachment, macular abnormalities, and } \\
\text { occipital encephalocele. }\end{array}$ \\
\hline KERA & Keratocan & $12 q 21.33$ & $\begin{array}{l}603288 \\
217300\end{array}$ & Cornea plana 2, autosomal recessive & $\begin{array}{l}\text { Reduced corneal curvature, hyperopia, hazy } \\
\text { corneal limbus, and arcus lipoides. }\end{array}$ \\
\hline
\end{tabular}

Simpson-Golabi-Behmel syndrome is an X-linked syndrome, caused by mutations in GPC3, and characterized by pre- and postnatal overgrowth, visceral and skeletal anormalies, a coarse face, heart defects, and hypotonia (Table 6; Veugelers et al., 2000; Sakazume et al., 2007). Keipert syndrome, known as nasodigitoacoustic syndrome, is also an X-linked syndrome, caused by mutations in GPC4, and characterized by craniofacial and digital abnormalities, variable learning difficulties, and sensorineural deafness (Table 6; Amor et al., 2019). Autosomalrecessive omodysplasia is caused by homozygous mutations in GPC6, and is characterized by proximally shortened limbs, facial dysmorphism, a severely short stature, and hypoplastic humeri (Table 6; Campos-Xavier et al., 2009).

Perlecan encoded by HSPG2 consists of a protein with 4,392 amino acids $(\sim 467 \mathrm{kDa})$, which is a major HS-PG with two or three HS as well as one or two CS, distributed to the basement membrane as well as the extracellular matrix of muscle, cartilage, and bone marrow (Cohen et al., 1993;
Nicole et al., 2000; Melrose, 2020). Schwartz-Jampel syndrome is an autosomal recessive disorder, caused by homozygous or compound heterozygous mutations in HSPG2, and characterized by permanent myotonia and skeletal dysplasia including a short stature, kyphoscoliosis, bowing of the diaphysis, and irregular epiphyses (Table 6; Nicole et al., 2000; Arikawa-Hirasawa et al., 2002; Stum et al., 2006). Dyssegmental dysplasia SilvermanHandmaker type is an autosomal recessive skeletal dysplasia with anisospondyly and micromelia, and is caused by homozygous or heterozygous mutations in HSPG2 (Table 6; Arikawa-Hirasawa et al., 2001). The probands showed the hallmarks including a flat face, micrognathia, cleft palate, reduced joint mobility, and encephalocele.

Agrin encoded by $A G R N$ consists of a protein with 2,068 amino acids, which has three potential HS attachments sites, and an extracellular matrix molecule released by the nerve and critical for formation of the neuromuscular junction (Rupp et al., 1991, 1992; Denzer et al., 1995). Myasthenic syndrome is a 
neuromuscular transmission disorder characterized by a major disorganization of the neuromuscular junction such as changes in the nerve-terminal cytoskeleton and fragmentation of the synaptic gutters, thereby leading to muscle weakness, caused by homozygous or heterozygous mutations in AGRN (Table 6; Huzé et al., 2009; Maselli et al., 2012).

Collagen $18 \alpha 1$ encoded by COL18A1 consists of a protein with 1,339 amino acids, which is a subfamily of collagen predominantly expressed in the extracellular matrix of the liver, lung, and kidney, and is a subfamily of collagen distributed in the extracellular matrix (Oh et al., 1994). Knobloch syndrome type 1 is an autosomal recessive disorder defined by the occurrence of high myopia, vitreoretinal degeneration with retinal detachment, macular abnormalities, and occipital encephalocele, which is caused by homozygous or compound heterozygous mutations in COL18A1 (Table 5; Sertié et al., 2000; Suzuki et al., 2002; Caglayan et al., 2014).

\section{Kepatan Sulfate-Proteoglycans}

Keratocan encoded by KERA consists of a protein core of 352 amino acids with three covalent $\mathrm{KS}$ attachment sites at asparagine residues (Corpuz et al., 1996). Cornea plana type 2 is autosomal recessive and a more severe disease than type 1 , characterized by a reduced corneal curvature, hyperopia, hazy corneal limbus, and arcus lipoides, and is caused by homozygous mutations in KERA (Table 6; Tahvanainen et al., 1996; Pellegata et al., 2000).

\section{CONCLUSION AND PERSPECTIVES}

Genomic sequences have led to the identification of a variety of congenital disorders caused by defects in anabolism and catabolism of GAGs as well as PGs. Some of them have common

\section{REFERENCES}

Ahmad, M., Faiyaz Ul Haque, M., Ahmad, W., Abbas, H., Haque, S., Krakow, D., et al. (1998). Distinct, autosomal recessive form of spondyloepimetaphyseal dysplasia segregating in an inbred Pakistani kindred. Am. J. Med. Genet. 78, 468-473. doi: 10.1002/(sici)1096-8628(19980806)78:5<468::aid-ajmg13>3.0. co;2-d

Ahn, J., Lüdecke, H. J., Lindow, S., Horton, W. A., Lee, B., Wagner, M. J., et al. (1995). Cloning of the putative tumour suppressor gene for hereditary multiple exostoses (EXT1). Nat. Genet. 11, 137-143. doi: 10.1038/ng109 $5-137$

Akama, T. O., Misra, A. K., Hindsgaul, O., and Fukuda, M. N. (2002). Enzymatic synthesis in vitro of the disulfated disaccharide unit of corneal keratan sulfate. J. Biol. Chem. 277, 42505-42513. doi: 10.1074/jbc.m207412200

Akama, T. O., Nakayama, J., Nishida, K., Hiraoka, N., Suzuki, M., McAuliffe, J., et al. (2001). Human corneal GlcNac 6-O-sulfotransferase and mouse intestinal GlcNac 6-O-sulfotransferase both produce keratan sulfate. J. Biol. Chem. 276, 16271-16278. doi: 10.1074/jbc.m009995200

Akama, T. O., Nishida, K., Nakayama, J., Watanabe, H., Ozaki, K., Nakamura, T., et al. (2000). Macular corneal dystrophy type I and type II are caused by distinct mutations in a new sulphotransferase gene. Nat. Genet. 26, 237-241. doi: $10.1038 / 79987$

Akatsu, C., Mizumoto, S., Kaneiwa, T., Maccarana, M., Malmström, A., Yamada, S., et al. (2011). Dermatan sulfate epimerase 2 is the predominant isozyme in the formation of the chondroitin sulfate/dermatan sulfate hybrid structure in postnatal developing mouse brain. Glycobiology 21, 565-574. doi: 10.1093/ glycob/cwq208 clinical features such as skeletal, skin, heart, neuronal, and immune abnormalities. However, the molecular mechanisms of the onsets underlying these congenital diseases remain to be elucidated. To clarify the molecular pathogeneses including analyses of the functional domains of GAGs, identifications of the affected core proteins of PGs, the functional proteins interacting with GAGs, and the signaling pathways transduced by GAGs, are required. Achievement of these analyses lead to new therapeutics including the applications of adeno-associated virus, enzymereplacement therapy, oligosaccharides derived from GAGs, and mimetics of GAGs for these disorders.

\section{AUTHOR CONTRIBUTIONS}

SM wrote the manuscript. SY provided fruitful comments. Both authors contributed to the article and approved the submitted version.

\section{FUNDING}

This work was supported in part by a Grant-in Aid for Scientific Research (C) 19K07054 (to SM) from the Japan Society for the Promotion of Science, Japan. Grant-in Aid for Research Center for Pathogenesis of Intractable Diseases from the Research Institute of Meijo University (SM and SY).

\section{ACKNOWLEDGMENTS}

We thank Medical English Service for editing the English text of the draft of this manuscript.

Alazami, A. M., Al-Qattan, S. M., Faqeih, E., Alhashem, A., Alshammari, M., Alzahrani, F., et al. (2016). Expanding the clinical and genetic heterogeneity of hereditary disorders of connective tissue. Hum. Genet. 135, 525-540. doi: 10.1007/s00439-016-1660-Z

Aldave, A. J., Yellore, V. S., Thonar, E. J., Udar, N., Warren, J. F., Yoon, M. K., et al. (2004). Novel mutations in the carbohydrate sulfotransferase gene (CHST6) in American patients with macular corneal dystrophy. Am. J. Ophthal. 137, 465-473. doi: 10.1016/j.ajo.2003.09.036

Al-Jezawi, N. K., Ali, B. R., and Al-Gazali, L. (2017). Endoplasmic reticulum retention of xylosyltransferase 1 (XYLT1) mutants underlying Desbuquois dysplasia type II. Am. J. Med. Genet. A 173, 1773-1781. doi: 10.1002/ajmg.a. 38244

Almeida, R., Levery, S. B., Mandel, U., Kresse, H., Schwientek, T., Bennett, E. P., et al. (1999). Cloning and expression of a proteoglycan UDP-galactose:betaxylose $\beta 1$,4-galactosyltransferase I. A seventh member of the human $\beta 4$ galactosyltransferase gene family. J. Biol. Chem. 274, 26165-26171.

Amor, D. J., Stephenson, S. E. M., Mustapha, M., Mensah, M. A., Ockeloen, C. W., Lee, W. S., et al. (2019). Pathogenic variants in GPC4 cause Keipert syndrome. Am. J. Hum. Genet. 104, 914-924. doi: 10.1016/j.ajhg.2019.02.026

Arikawa-Hirasawa, E., Le, A. H., Nishino, I., Nonaka, I., Ho, N. C., Francomano, C. A., et al. (2002). Structural and functional mutations of the perlecan gene cause Schwartz-Jampel syndrome, with myotonic myopathy and chondrodysplasia. Am. J. Hum. Genet. 70, 1368-1375. doi: 10.1086/340390

Arikawa-Hirasawa, E., Wilcox, W. R., Le, A. H., Silverman, N., Govindraj, P., Hassell, J. R., et al. (2001). Dyssegmental dysplasia, Silverman-Handmaker type, is caused by functional null mutations of the perlecan gene. Nat. Genet. 27, 431-434. doi: $10.1038 / 86941$ 
Armstrong, L., Tarailo-Graovac, M., Sinclair, G., Seath, K. I., Wasserman, W. W., Ross, C. J., et al. (2017). A girl with developmental delay, ataxia, cranial nerve palsies, severe respiratory problems in infancy-Expanding NDST1 syndrome. Am. J. Med. Genet. A 173, 712-715. doi: 10.1002/ajmg.a.37621

Arunrut, T., Sabbadini, M., Jain, M., Machol, K., Scaglia, F., and Slavotinek, A. (2016). Corneal clouding, cataract, and colobomas with a novel missense mutation in B4GALT7-a review of eye anomalies in the linkeropathy syndromes. Am. J. Med. Genet. A 170, 2711-2718. doi: 10.1002/ajmg.a.37809

Baasanjav, S., Al-Gazali, L., Hashiguchi, T., Mizumoto, S., Fischer, B., Horn, D., et al. (2011). Faulty initiation of proteoglycan synthesis causes cardiac and joint defects. Am. J. Hum. Genet. 89, 15-27. doi: 10.1016/j.ajhg.2011.05.021

Bai, X., Zhou, D., Brown, J. R., Crawford, B. E., Hennet, T., and Esko, J. D. (2001). Biosynthesis of the linkage region of glycosaminoglycans: cloning and activity of galactosyltransferase II, the sixth member of the $\beta 1,3$-galactosyltransferase family (B3GalT6). J. Biol. Chem. 276, 48189-48195.

Balasubramanian, K., Li, B., Krakow, D., Nevarez, L., Ho, P. J., Ainsworth, J. A., et al. (2017). MED resulting from recessively inherited mutations in the gene encoding calcium-activated nucleotidase CANT1. Am. J. Med. Genet. A 173, 2415-2421. doi: 10.1002/ajmg.a.38349

Baratela, W. A., Bober, M. B., Tiller, G. E., Okenfuss, E., Ditro, C., Duker, A., et al. (2012). A newly recognized syndrome with characteristic facial features, skeletal dysplasia, and developmental delay. Am. J. Med. Genet. A 158A, 1815-1822. doi: 10.1002/ajmg.a.35445

Bartolini, B., Thelin, M. A., Rauch, U., Feinstein, R., Oldberg, A., Malmström, A., et al. (2012). Mouse development is not obviously affected by the absence of dermatan sulfate epimerase 2 in spite of a modified brain dermatan sulfate composition. Glycobiology 22, 1007-1016. doi: 10.1093/glycob/cws065

Beighton, P., Gericke, G., Kozlowski, K., and Grobler, L. (1984). The manifestations and natural history of spondylo-epi-metaphyseal dysplasia with joint laxity. Clin. Genet. 26, 308-317. doi: 10.1111/j.1399-0004.1984.tb01065.x

Berninsone, P. M., and Hirschberg, C. B. (2000). Nucleotide sugar transporters of the Golgi apparatus. Curr. Opin. Struct. Biol. 10, 542-547. doi: 10.1016/s0959440x(00)00128-7

Bick, D., Franco, B., Sherins, R. J., Heye, B., Pike, L., Crawford, J., et al. (1992). Brief report: intragenic deletion of the KALIG-1 gene in Kallmann's syndrome. New Eng. J. Med. 326, 1752-1755.

Bishop, J. R., Schuksz, M., and Esko, J. D. (2007). Heparan sulphate proteoglycans fine-tune mammalian physiology. Nature 446, 1030-1037. doi: 10.1038/ nature 05817

Boehm, U., Bouloux, P. M., Dattani, M. T., de Roux, N., Dodé, C., Dunkel, L., et al. (2015). Expert consensus document: European Consensus Statement on congenital hypogonadotropic hypogonadism-pathogenesis, diagnosis and treatment. Nat. Rev. Endocrinol. 11, 547-564. doi: 10.1038/nrendo.2015.112

Bovée, J. V., Cleton-Jansen, A. M., Wuyts, W., Caethoven, G., Taminiau, A. H., Bakker, E., et al. (1999). EXT-mutation analysis and loss of heterozygosity in sporadic and hereditary osteochondromas and secondary chondrosarcomas. Am. J. Hum. Genet. 65, 689-698. doi: 10.1086/302532

Bownass, L., Abbs, S., Armstrong, R., Baujat, G., Behzadi, G., Berentsen, R. D., et al. (2019). PAPSS2-related brachyolmia: Clinical and radiological phenotype in 18 new cases. Am. J. Med. Genet. A 179, 1884-1894.

Bredrup, C., Knappskog, P. M., Majewski, J., Rødahl, E., and Boman, H. (2005). Congenital stromal dystrophy of the cornea caused by a mutation in the decorin gene. Invest. Ophthalmol. Vis. Sci. 46, 420-426. doi: 10.1167/iovs.04-0804

Broussard, A., Florwick, A., Desbiens, C., Nischan, N., Robertson, C., Guan, Z., et al. (2020). Human UDP-galactose $4^{\prime}$-epimerase (GALE) is required for cellsurface glycome structure and function. J. Biol. Chem. 295, 1225-1239. doi: 10.1016/s0021-9258(17)49882-6

Budde, B. S., Mizumoto, S., Kogawa, R., Becker, C., Altmüller, J., Thiele, H., et al. (2015). Skeletal dysplasia in a consanguineous clan from the island of Nias/Indonesia is caused by a novel mutation in B3GAT3. Hum. Genet. 134, 691-704. doi: 10.1007/s00439-015-1549-2

Bui, C., Huber, C., Tuysuz, B., Alanay, Y., Bole-Feysot, C., Leroy, J. G., et al. (2014). XYLT1 mutations in Desbuquois dysplasia type 2. Am. J. Hum. Genet. 94, 405-414. doi: 10.1016/j.ajhg.2014.01.020

Bülow, H. E., and Hobert, O. (2006). The molecular diversity of glycosaminoglycans shapes animal development. Annu. Rev. Cell Dev. Biol. 22, 375-407. doi: 10.1146/annurev.cellbio.22.010605.093433
Byrne, A. B., Mizumoto, S., Arts, P., Yap, P., Feng, J., Schreiber, A. W., et al. (2020). Pseudodiastrophic dysplasia expands the known phenotypic spectrum of defects in proteoglycan biosynthesis. J. Med. Genet. 57, 454-460. doi: 10.1136/ jmedgenet-2019-106700

Caglayan, A. O., Baranoski, J. F., Aktar, F., Han, W., Tuysuz, B., Guzel, A., et al. (2014). Brain malformations associated with Knobloch syndrome-review of literature, expanding clinical spectrum, and identification of novel mutations. Pediatr. Neurol. 51, 806-813. doi: 10.1016/j.pediatrneurol.2014.08.025

Campos-Xavier, A. B., Martinet, D., Bateman, J., Belluoccio, D., Rowley, L., Tan, T. Y., et al. (2009). Mutations in the heparan-sulfate proteoglycan glypican 6 (GPC6) impair endochondral ossification and cause recessive omodysplasia. Am. J. Hum. Genet. 84, 760-770. doi: 10.1016/j.ajhg.2009.05.002

Cartault, F., Munier, P., Jacquemont, M. L., Vellayoudom, J., Doray, B., Payet, C., et al. (2015). Expanding the clinical spectrum of B4GALT7 deficiency: homozygous p.R270C mutation with founder effect causes Larsen of Reunion Island syndrome. Eur. J. Hum. Genet. 23, 49-53. doi: 10.1038/ejhg.2014.60

Chan, W. L., Steiner, M., Witkos, T., Egerer, J., Busse, B., Mizumoto, S., et al. (2018). Impaired proteoglycan glycosylation, elevated TGF- $\beta$ signaling, and abnormal osteoblast differentiation as the basis for bone fragility in a mouse model for gerodermia osteodysplastica. PLoS Genet. 14:e1007242. doi: 10.1371/journal. pgen.1007242

Chen, S., Sun, M., Meng, X., Iozzo, R. V., Kao, W. W., and Birk, D. E. (2011). Pathophysiological mechanisms of autosomal dominant congenital stromal corneal dystrophy: C-terminal-truncated decorin results in abnormal matrix assembly and altered expression of small leucine-rich proteoglycans. Am. J. Pathol. 179, 2409-2419.

Cheung, P. K., McCormick, C., Crawford, B. E., Esko, J. D., Tufaro, F., and Duncan, G. (2001). Etiological point mutations in the hereditary multiple exostoses gene EXT1: a functional analysis of heparan sulfate polymerase activity. Am. J. Hum. Genet. 69, 55-66. doi: 10.1086/321278

Cho, S. Y., Bae, J. S., Kim, N. K. D., Forzano, F., Girisha, K. M., Baldo, C., et al. (2016). BGN mutations in X-linked spondyloepimetaphyseal dysplasia. Am. J. Hum. Genet. 98, 1243-1248.

Chopra, S. S., Leshchiner, I., Duzkale, H., McLaughlin, H., Giovanni, M., Zhang, C., et al. (2015). Inherited CHST11/MIR3922 deletion is associated with a novel recessive syndrome presenting with skeletal malformation and malignant lymphoproliferative disease. Mol. Genet. Genomic Med. 3, 413-423. doi: 10. 1002/mgg3.152

Climer, L. K., Pokrovskaya, I. D., Blackburn, J. B., and Lupashin, V. V. (2018). Membrane detachment is not essential for COG complex function. Mol. Biol. Cell 29, 964-974. doi: 10.1091/mbc.e17-11-0694

Cohen, I. R., Grässel, S., Murdoch, A. D., and Iozzo, R. V. (1993). Structural characterization of the complete human perlecan gene and its promoter. Proc. Natl. Acad. Sci. U. S. A. 90, 10404-10408. doi: 10.1073/pnas.90.21.10404

Corpuz, L. M., Funderburgh, J. L., Funderburgh, M. L., Bottomley, G. S., Prakash, S., and Conrad, G. W. (1996). Molecular cloning and tissue distribution of keratocan. Bovine corneal keratan sulfate proteoglycan 37A. J. Biol. Chem. 271, 9759-9763.

Dai, J., Kim, O. H., Cho, T. J., Miyake, N., Song, H. R., Karasugi, T., et al. (2011). A founder mutation of CANT1 common in Korean and Japanese Desbuquois dysplasia. J. Hum. Genet. 56, 398-400. doi: 10.1038/jhg.2011.28

Denzer, A. J., Gesemann, M., Schumacher, B., and Ruegg, M. A. (1995). An aminoterminal extension is required for the secretion of chick agrin and its binding to extracellular matrix. J. Cell Biol. 131, 1547-1560. doi: 10.1083/jcb.131.6.1547

Desbuquois, G., Grenier, B., Michel, J., and Rossignol, C. (1966). Nanisme chondrodystrophique avec ossification anarchique et polymalformations chez deux sœurs. Arch. Franc. Pediat. 23, 573-587.

Dixon, J., Loftus, S. K., Gladwin, A. J., Scambler, P. J., Wasmuth, J. J., and Dixon, M. J. (1995). Cloning of the human heparan sulfate- $N$-deacetylase $/ N$ sulfotransferase gene from the treacher Collins syndrome candidate region at 5q32-q33.1. Genomics 26, 239-244. doi: 10.1016/0888-7543(95)80206-2

Dodé, C., Levilliers, J., Dupont, J. M., De Paepe, A., Le Dû, N., Soussi-Yanicostas, N., et al. (2003). Loss-of-function mutations in FGFR1 cause autosomal dominant Kallmann syndrome. Nat. Genet. 33, 463-465.

Doege, K. J., Sasaki, M., Kimura, T., and Yamada, Y. (1991). Complete coding sequence and deduced primary structure of the human cartilage large aggregating proteoglycan, aggrecan. Human-specific repeats, and additional 
alternatively spliced forms. J. Biol. Chem. 266, 894-902. doi: 10.1016/s00219258(17)35257-2

Dours-Zimmermann, M. T., and Zimmermann, D. R. (1994). A novel glycosaminoglycan attachment domain identified in two alternative splice variants of human versican. J. Biol. Chem. 269, 32992-32998. doi: 10.1016/ s0021-9258(20)30089-2

Dundar, M., Demiryilmaz, F., Demiryilmaz, I., Kumandas, S., Erkilic, K., Kendirci, M., et al. (1997). An autosomal recessive adducted thumb-club foot syndrome observed in Turkish cousins. Clin. Genet. 51, 61-64. doi: 10.1111/j.1399-0004. 1997.tb02417.x

Dündar, M., Müller, T., Zhang, Q., Pan, J., Steinmann, B., Vodopiutz, J., et al. (2009). Loss of dermatan-4-sulfotransferase 1 function results in adducted thumb-clubfoot syndrome. Am. J. Hum. Genet. 85, 873-882. doi: 10.1016/j. ajhg.2009.11.010

Edmondson, A. C., Bedoukian, E. C., Deardorff, M. A., McDonald-McGinn, D. M., Li, X., He, M., et al. (2017). A human case of SLC35A3-related skeletal dysplasia. Am. J. Med. Genet. A 173, 2758-2762. doi: 10.1002/ajmg.a.38374

Edvardson, S., Ashikov, A., Jalas, C., Sturiale, L., Shaag, A., Fedick, A., et al. (2013). Mutations in SLC35A3 cause autism spectrum disorder, epilepsy and arthrogryposis. J. Med. Genet. 50, 733-739. doi: 10.1136/jmedgenet-2013101753

El-Ashry, M. F., Abd El-Aziz, M. M., Wilkins, S., Cheetham, M. E., Wilkie, S. E., Hardcastle, A. J., et al. (2002). Identification of novel mutations in the carbohydrate sulfotransferase gene (CHST6) causing macular corneal dystrophy. Invest. Ophthal. Vis. Sci. 43, 377-382.

Eteson, D. J., Beluffi, G., Burgio, G. R., Belloni, C., Lachman, R. S., and Rimoin, D. L. (1986). Pseudodiastrophic dysplasia: a distinct newborn skeletal dysplasia. J. Pediatr. 109, 635-641. doi: 10.1016/s0022-3476(86)80227-x

Evers, M. R., Xia, G., Kang, H. G., Schachner, M., and Baenziger, J. U. (2001). Molecular cloning and characterization of a dermatan-specific $\mathrm{N}$-acetylgalactosamine 4-O-sulfotransferase. J. Biol. Chem. 276, 36344-36353.

Faden, M., Al-Zahrani, F., Arafah, D., and Alkuraya, F. S. (2010). Mutation of CANT1 causes Desbuquois dysplasia. Am. J. Med. Genet. A 152A, 1157-1160.

Failer, B. U., Braun, N., and Zimmermann, H. (2002). Cloning, expression, and functional characterization of a $\mathrm{Ca}^{2+}$-dependent endoplasmic reticulum nucleoside diphosphatase. J. Biol. Chem. 277, 36978-36986. doi: 10.1074/jbc. $\mathrm{m} 201656200$

Faiyaz-Ul-Haque, M., Ahmad, W., Zaidi, S. H., Hussain, S., Haque, S., Ahmad, M., et al. (2004). Novel mutations in the EXT1 gene in two consanguineous families affected with multiple hereditary exostoses (familial osteochondromatosis). Clin. Genet. 66, 144-151. doi: 10.1111/j.1399-0004.2004.00275.x

Falardeau, J., Chung, W. C., Beenken, A., Raivio, T., Plummer, L., Sidis, Y., et al. (2008). Decreased FGF8 signaling causes deficiency of gonadotropin-releasing hormone in humans and mice. J. Clin. Invest. 118, 2822-2831. doi: 10.1172/ jci34538

Farhan, S. M., Wang, J., Robinson, J. F., Prasad, A. N., Rupar, C. A., Siu, V. M., et al. (2015). Old gene, new phenotype: mutations in heparan sulfate synthesis enzyme, EXT2 leads to seizure and developmental disorder, no exostoses. J. Med. Genet. 52, 666-675. doi: 10.1136/jmedgenet-2015-103279

Ferreira, C. R., Xia, Z. J., Clément, A., Parry, D. A., Davids, M., Taylan, F., et al. (2018). A Recurrent De Novo Heterozygous COG4 substitution leads to SaulWilson syndrome, disrupted vesicular trafficking, and altered proteoglycan glycosylation. Am. J. Hum. Genet. 103, 553-567. doi: 10.1016/j.ajhg.2018.09.003

Filmus, J., and Capurro, M. (2014). The role of glypicans in Hedgehog signaling. Matrix Biol. 35, 248-252. doi: 10.1016/j.matbio.2013.12.007

Filmus, J., Capurro, M., and Rast, J. (2008). Glypicans. Genome Biol. 9:224. doi: 10.1186/gb-2008-9-5-224

Fischer, S., Filipek-Gorniok, B., and Ledin, J. (2011). Zebrafish Ext2 is necessary for Fgf and Wnt signaling, but not for Hh signaling. BMC Dev. Biol. 11:53. doi: 10.1186/1471-213X-11-53

Fischetto, R., Causio, F., Corso, G., Lillo, V., Natale, B., and Papadia, F. (1997). Pseudodiastrophic dysplasia type Burgio in a newborn. Am. J. Med. Genet. 71, 222-225. doi: 10.1002/(sici)1096-8628(19970808)71:2<222::aid-ajmg20>3. $0 . \mathrm{co} ; 2-\mathrm{f}$

Fisher, L. W., Termine, J. D., and Young, M. F. (1989). Deduced protein sequence of bone small proteoglycan I (biglycan) shows homology with proteoglycan II (decorin) and several nonconnective tissue proteins in a variety of species. J. Biol. Chem. 264, 4571-4576. doi: 10.1016/s0021-9258(18)83781-4
Frederick, J. P., Tafari, A. T., Wu, S. M., Megosh, L. C., Chiou, S. T., Irving, R. P., et al. (2008). A role for a lithium-inhibited Golgi nucleotidase in skeletal development and sulfation. Proc. Natl. Acad. Sci. U. S. A. 105, 11605-11612.

Freeze, H. H., Eklund, E. A., Ng, B. G., and Patterson, M. C. (2015). Neurological aspects of human glycosylation disorders. Annu. Rev. Neurosci. 38, 105-125. doi: 10.1146/annurev-neuro-071714-034019

Fuda, H., Shimizu, C., Lee, Y. C., Akita, H., and Strott, C. A. (2002). Characterization and expression of human bifunctional $3^{\prime}$-phosphoadenosine $5^{\prime}$-phosphosulphate synthase isoforms. Biochem. J. 365, 497-504. doi: 10.1042/ bj20020044

Fukuta, M., Inazawa, J., Torii, T., Tsuzuki, K., Shimada, E., and Habuchi, O. (1997). Molecular cloning and characterization of human keratan sulfate Gal6-sulfotransferase. J. Biol. Chem. 272, 32321-32328. doi: 10.1074/jbc.272.51. 32321

Fukuta, M., Kobayashi, Y., Uchimura, K., Kimata, K., and Habuchi, O. (1998). Molecular cloning and expression of human chondroitin 6-sulfotransferase. Biochim. Biophys. Acta 1399, 57-61. doi: 10.1016/s0167-4781(98)00089-x

Furuichi, T., Dai, J., Cho, T. J., Sakazume, S., Ikema, M., Matsui, Y., et al. (2011). CANT1 mutation is also responsible for Desbuquois dysplasia, type 2 and Kim variant. J. Med. Genet. 48, 32-37. doi: 10.1136/jmg.2010.08 0226

Furuichi, T., Kayserili, H., Hiraoka, S., Nishimura, G., Ohashi, H., Alanay, Y., et al. (2009). Identification of loss-of-function mutations of SLC35D1 in patients with Schneckenbecken dysplasia, but not with other severe spondylodysplastic dysplasias group diseases. J. Med. Genet. 46, 562-568. doi: 10.1136/jmg.2008. 065201

Fushinobu, S. (2021). Molecular evolution and functional divergence of UDPhexose 4-epimerases. Curr. Opin. Chem. Biol. 61, 53-62. doi: 10.1016/j.cbpa. 2020.09.007

García-García, M. J., and Anderson, K. V. (2003). Essential role of glycosaminoglycans in Fgf signaling during mouse gastrulation. Cell 114, 727-737. doi: 10.1016/s0092-8674(03)00715-3

Gleghorn, L., Ramesar, R., Beighton, P., and Wallis, G. (2005). A mutation in the variable repeat region of the aggrecan gene (AGC1) causes a form of spondyloepiphyseal dysplasia associated with severe, premature osteoarthritis. Am. J. Hum. Genet. 77, 484-490. doi: 10.1086/444401

González-Martínez, D., Kim, S. H., Hu, Y., Guimond, S., Schofield, J., Winyard, P., et al. (2004). Anosmin-1 modulates fibroblast growth factor receptor 1 signaling in human gonadotropin-releasing hormone olfactory neuroblasts through a heparan sulfate-dependent mechanism. J. Neurosci. 24, 10384-10392. doi: 10. 1523/jneurosci.3400-04.2004

Goossens, D., Van Gestel, S., Claes, S., De Rijk, P., Souery, D., Massat, I., et al. (2003). A novel CpG-associated brain-expressed candidate gene for chromosome 18q-linked bipolar disorder. Mol. Psychiatry 8, 83-89. doi: 10 . 1038/sj.mp.4001190

Götte, M., Spillmann, D., Yip, G. W., Versteeg, E., Echtermeyer, F. G., van Kuppevelt, T. H., et al. (2008). Changes in heparan sulfate are associated with delayed wound repair, altered cell migration, adhesion and contractility in the galactosyltransferase I ( $\beta 4 \mathrm{GalT}-7)$ deficient form of Ehlers-Danlos syndrome. Hum. Mol. Genet. 17, 996-1009. doi: 10.1093/hmg/ddm372

Götting, C., Kuhn, J., Zahn, R., Brinkmann, T., and Kleesiek, K. (2000). Molecular cloning and expression of human UDP-D-Xylose:proteoglycan core protein $\beta$-D-xylosyltransferase and its first isoform XT-II. J. Mol. Biol. 304, 517-528. doi: 10.1006/jmbi.2000.4261

Gulberti, S., Lattard, V., Fondeur, M., Jacquinet, J. C., Mulliert, G., Netter, P., et al. (2005). Phosphorylation and sulfation of oligosaccharide substrates critically influence the activity of human $\beta 1$,4-galactosyltransferase 7 (GalT-I) and $\beta 1,3$-glucuronosyltransferase I (GlcAT-I) involved in the biosynthesis of the glycosaminoglycan-protein linkage region of proteoglycans. J. Biol. Chem. 280, 1417-1425. doi: 10.1074/jbc.m411552200

Guo, L., Elcioglu, N. H., Iida, A., Demirkol, Y. K., Aras, S., Matsumoto, N., et al. (2017a). Novel and recurrent XYLT1 mutations in two Turkish families with Desbuquois dysplasia, type 2. J. Hum. Genet. 62, 447-451. doi: 10.1038/jhg. 2016.143

Guo, L., Elcioglu, N. H., Mizumoto, S., Wang, Z., Noyan, B., Albayrak, H. M., et al. (2017b). Identification of biallelic EXTL3 mutations in a novel type of spondyloepi-metaphyseal dysplasia. J. Hum. Genet. 62, 797-801. doi: 10.1038/jhg. 2017.38 
Guo, M. H., Stoler, J., Lui, J., Nilsson, O., Bianchi, D. W., Hirschhorn, J. N., et al. (2013). Redefining the progeroid form of Ehlers-Danlos syndrome: report of the fourth patient with B4GALT7 deficiency and review of the literature. Am. J. Med. Genet. A. 161A, 2519-2527.

Habuchi, H., Kobayashi, M., and Kimata, K. (1998). Molecular characterization and expression of heparan-sulfate 6-sulfotransferase. Complete cDNA cloning in human and partial cloning in Chinese hamster ovary cells. J. Biol. Chem. 273, 9208-9213.

Habuchi, H., Tanaka, M., Habuchi, O., Yoshida, K., Suzuki, H., Ban, K., et al. (2000). The occurrence of three isoforms of heparan sulfate 6-O-sulfotransferase having different specificities for hexuronic acid adjacent to the targeted $N$-sulfoglucosamine. J. Biol. Chem. 275, 2859-2868.

Häcker, U., Nybakken, K., and Perrimon, N. (2005). Heparan sulphate proteoglycans: the sweet side of development. Nat. Rev. Mol. Cell Biol. 6, 530-541. doi: 10.1038/nrm1681

Haouari, W., Dubail, J., Lounis-Ouaras, S., Prada, P., Bennani, R., Roseau, C., et al. (2020). Serum bikunin isoforms in congenital disorders of glycosylation and linkeropathies. J. Inherit. Metab. Dis. 43, 1349-1359. doi: 10.1002/jimd.1 2291

Hashimoto, Y., Orellana, A., Gil, G., and Hirschberg, C. B. (1992). Molecular cloning and expression of rat liver $N$-heparan sulfate sulfotransferase. J. Biol. Chem. 267, 15744-15750. doi: 10.1016/s0021-9258(19)49598-7

Hästbacka, J., de la Chapelle, A., Mahtani, M. M., Clines, G., Reeve-Daly, M. P., Daly, M., et al. (1994). The diastrophic dysplasia gene encodes a novel sulfate transporter: positional cloning by fine-structure linkage disequilibrium mapping. Cell 78, 1073-1087. doi: 10.1016/0092-8674(94)90281-x

Hästbacka, J., Superti-Furga, A., Wilcox, W. R., Rimoin, D. L., Cohn, D. H., and Lander, E. S. (1996). Atelosteogenesis type II is caused by mutations in the diastrophic dysplasia sulfate-transporter gene (DTDST): evidence for a phenotypic series involving three chondrodysplasias. Am. J. Hum. Genet. 58, $255-262$.

Hengel, H., Bosso-Lefèvre, C., Grady, G., Szenker-Ravi, E., Li, H., Pierce, S., et al. (2020). Loss-of-function mutations in UDP-glucose 6-dehydrogenase cause recessive developmental epileptic encephalopathy. Nat. Commun. 11:595. doi: 10.1038/s41467-020-14360-7

Hennekam, R. C. M. (1991). Hereditary multiple exostoses. J. Med. Genet. 28, $262-266$.

Hennies, H. C., Kornak, U., Zhang, H., Egerer, J., Zhang, X., Seifert, W., et al. (2008). Gerodermia osteodysplastica is caused by mutations in SCYL1BP1, a Rab-6 interacting golgin. Nat. Genet. 40, 1410-1412. doi: 10.1038/ng.252

Hermanns, P., Unger, S., Rossi, A., Perez-Aytes, A., Cortina, H., Bonafe, L., et al. (2008). Congenital joint dislocations caused by carbohydrate sulfotransferase 3 deficiency in recessive Larsen syndrome and humero-spinal dysostosis. Am. J. Hum. Genet. 82, 1368-1374. doi: 10.1016/j.ajhg.2008.05.006

Hiraoka, N., Nakagawa, H., Ong, E., Akama, T. O., Fukuda, M. N., and Fukuda, M. (2000). Molecular cloning and expression of two distinct human chondroitin 4-O-sulfotransferases that belong to the HNK-1 sulfotransferase gene family. J. Biol. Chem. 275, 20188-20196. doi: 10.1074/jbc.m002443200

Hiraoka, S., Furuichi, T., Nishimura, G., Shibata, S., Yanagishita, M., Rimoin, D. L., et al. (2007). Nucleotide-sugar transporter SLC35D1 is critical to chondroitin sulfate synthesis in cartilage and skeletal development in mouse and human. Nat. Med. 13, 1363-1367. doi: 10.1038/nm1655

Hirose, T., Mizumoto, S., Hashimoto, A., Takahashi, Y., Yoshizawa, T., NitaharaKasahara, Y., et al. (2021). Systematic investigation of the skin in Chst14-/mice: A model for skin fragility in musculocontractural Ehlers-Danlos syndrome caused by CHST14 variants (mcEDS-CHST14). Glycobiology 31, 137-150. doi: 10.1093/glycob/cwaa058

Hirose, T., Takahashi, N., Tangkawattana, P., Minaguchi, J., Mizumoto, S., Yamada, S., et al. (2019). Structural alteration of glycosaminoglycan side chains and spatial disorganization of collagen networks in the skin of patients with mcEDSCHST14. Biochim. Biophys. Acta Gen. Subj. 1863, 623-631. doi: 10.1016/j. bbagen.2018.12.006

Huber, C., Oulès, B., Bertoli, M., Chami, M., Fradin, M., Alanay, Y., et al. (2009). Identification of CANT1 mutations in Desbuquois dysplasia. Am. J. Hum. Genet. 85, 706-710. doi: 10.1016/j.ajhg.2009.10.001

Huzé, C., Bauché, S., Richard, P., Chevessier, F., Goillot, E., Gaudon, K., et al. (2009). Identification of an agrin mutation that causes congenital myasthenia and affects synapse function. Am. J. Hum. Genet. 85, 155-167.
Iida, A., Simsek-Kiper, P. Ö, Mizumoto, S., Hoshino, T., Elcioglu, N., Horemuzova, E., et al. (2013). Clinical and radiographic features of the autosomal recessive form of brachyolmia caused by PAPSS2 mutations. Hum. Mutat. 34, 1381-1386. doi: 10.1002/humu.22377

Iozzo, R. V. (1998). Matrix proteoglycans: from molecular design to cellular function. Annu. Rev. Biochem. 67, 609-652. doi: 10.1146/annurev.biochem.67. 1.609

Ishida, N., Yoshioka, S., Chiba, Y., Takeuchi, M., and Kawakita, M. (1999). Molecular cloning and functional expression of the human Golgi UDP$N$-acetylglucosamine transporter. J. Biochem. 126, 68-77. doi: 10.1093/ oxfordjournals.jbchem.a022437

Izumikawa, T., Koike, T., Shiozawa, S., Sugahara, K., Tamura, J., and Kitagawa, H. (2008). Identification of chondroitin sulfate glucuronyltransferase as chondroitin synthase-3 involved in chondroitin polymerization: chondroitin polymerization is achieved by multiple enzyme complexes consisting of chondroitin synthase family members. J. Biol. Chem. 283, 11396-11406. doi: 10.1074/jbc.m707549200

Izumikawa, T., Uyama, T., Okuura, Y., Sugahara, K., and Kitagawa, H. (2007). Involvement of chondroitin sulfate synthase-3 (chondroitin synthase-2) in chondroitin polymerization through its interaction with chondroitin synthase1 or chondroitin-polymerizing factor. Biochem. J. 403, 545-552. doi: 10.1042/ bj20061876

Janecke, A. R., Unsinn, K., Kreczy, A., Baldissera, I., Gassner, I., Neu, N., et al. (2001). Adducted thumb-club foot syndrome in sibs of a consanguineous Austrian family. J. Med. Genet. 38, 265-269. doi: 10.1136/jmg.38.4.265

Jing, Y., Kumar, P. R., Zhu, L., Edward, D. P., Tao, S., Wang, L., et al. (2014). Novel decorin mutation in a Chinese family with congenital stromal corneal dystrophy. Cornea 33, 288-293. doi: 10.1097/ico.0000000000000055

Job, F., Mizumoto, S., Smith, L., Couser, N., Brazil, A., Saal, H., et al. (2016). Functional validation of novel compound heterozygous variants in B3GAT3 resulting in severe osteopenia and fractures: expanding the disease phenotype. BMC Med. Genet. 17:86. doi: 10.1186/s12881-016-0344-9

Jones, K. L., Schwarze, U., Adam, M. P., Byers, P. H., and Mefford, H. C. (2015). A homozygous B3GAT3 mutation causes a severe syndrome with multiple fractures, expanding the phenotype of linkeropathy syndromes. Am. J. Med. Genet. A 167A, 2691-2696. doi: 10.1002/ajmg.a.37209

Kim, B. T., Kitagawa, H., Tamura, J., Saito, T., Kusche-Gullberg, M., Lindahl, U., et al. (2001). Human tumor suppressor EXT gene family members EXTL1 and EXTL3 encode $\alpha 1,4-N$-acetylglucosaminyltransferases that likely are involved in heparan sulfate/heparin biosynthesis. Proc. Natl. Acad. Sci. U. S. A. 98, 7176-7181. doi: 10.1073/pnas. 131188498

Kim, B. T., Kitagawa, H., Tanaka, J., Tamura, J., and Sugahara, K. (2003). In vitro heparan sulfate polymerization: crucial roles of core protein moieties of primer substrates in addition to the EXT1-EXT2 interaction. J. Biol. Chem. 278, $41618-41623$.

Kim, J. H., Ko, J. M., Lee, I., Kim, J. Y., Kim, M. J., and Tchah, H. (2011). A novel mutation of the decorin gene identified in a Korean family with congenital hereditary stromal dystrophy. Cornea 30, 1473-1477. doi: 10.1097/ ico.0b013e3182137788

Kitagawa, H., Izumikawa, T., Uyama, T., and Sugahara, K. (2003). Molecular cloning of a chondroitin polymerizing factor that cooperates with chondroitin synthase for chondroitin polymerization. J. Biol. Chem. 278, 23666-23671. doi: 10.1074/jbc.m302493200

Kitagawa, H., Shimakawa, H., and Sugahara, K. (1999). The tumor suppressor EXT-like gene EXTL2 encodes an $\alpha 1,4-N$-acetylhexosaminyltransferase that transfers $\mathrm{N}$-acetylgalactosamine and $\mathrm{N}$-acetylglucosamine to the common glycosaminoglycan-protein linkage region. The key enzyme for the chain initiation of heparan sulfate. J. Biol. Chem. 274, 13933-13937. doi: 10.1074/ jbc.274.20.13933

Kitagawa, H., Tone, Y., Tamura, J., Neumann, K. W., Ogawa, T., Oka, S., et al. (1998). Molecular cloning and expression of glucuronyltransferase I involved in the biosynthesis of the glycosaminoglycan-protein linkage region of proteoglycans. J. Biol. Chem. 273, 6615-6618. doi: 10.1074/jbc.273.12.6615

Kitagawa, H., Tsutsumi, K., Ikegami-Kuzuhara, A., Nadanaka, S., Goto, F., Ogawa, T., et al. (2008). Sulfation of the galactose residues in the glycosaminoglycan-protein linkage region by recombinant human chondroitin 6-O-sulfotransferase-1. J. Biol. Chem. 283, 27438-27443. doi: 10.1074/jbc. m803279200 
Kitagawa, H., Uyama, T., and Sugahara, K. (2001). Molecular cloning and expression of a human chondroitin synthase. J. Biol. Chem. 276, 38721-38726. doi: $10.1074 /$ jbc.m106871200

Kitayama, K., Hayashida, Y., Nishida, K., and Akama, T. O. (2007). Enzymes responsible for synthesis of corneal keratan sulfate glycosaminoglycans. J. Biol. Chem. 282, 30085-30096. doi: 10.1074/jbc.m703695200

Kloeckener-Gruissem, B., Bartholdi, D., Abdou, M. T., Zimmermann, D. R., and Berger, W. (2006). Identification of the genetic defect in the original wagner syndrome family. Mol. Vis. 12, 350-355.

Kloeckener-Gruissem, B., Neidhardt, J., Magyar, I., Plauchu, H., Zech, J. C., Morlé, L., et al. (2013). Novel VCAN mutations and evidence for unbalanced alternative splicing in the pathogenesis of wagner syndrome. Eur. J. Hum. Genet. 21, 352-356. doi: 10.1038/ejhg.2012.137

Kobayashi, M., Habuchi, H., Yoneda, M., Habuchi, O., and Kimata, K. (1997). Molecular cloning and expression of Chinese hamster ovary cell heparan-sulfate 2-sulfotransferase. J. Biol. Chem. 272, 13980-13985. doi: 10.1074/jbc.272.21. 13980

Koike, T., Izumikawa, T., Sato, B., and Kitagawa, H. (2014). Identification of phosphatase that dephosphorylates xylose in the glycosaminoglycan-protein linkage region of proteoglycans. J. Biol. Chem. 289, 6695-6708. doi: 10.1074/ jbc.m113.520536

Koike, T., Izumikawa, T., Tamura, J., and Kitagawa, H. (2009). FAM20B is a kinase that phosphorylates xylose in the glycosaminoglycan-protein linkage region. Biochem. J. 421, 157-162. doi: 10.1042/bj20090474

Kosho, T., Miyake, N., Hatamochi, A., Takahashi, J., Kato, H., Miyahara, T., et al. (2010). A new Ehlers-Danlos syndrome with craniofacial characteristics, multiple congenital contractures, progressive joint and skin laxity, and multisystem fragility-related manifestations. Am. J. Med. Genet. 152A, 13331346.

Kosho, T., Takahashi, J., Ohashi, H., Nishimura, G., Kato, H., and Fukushima, Y. (2005). Ehlers-Danlos syndrome type VIB with characteristic facies, decreased curvatures of the spinal column, and joint contractures in two unrelated girls. Am. J. Med. Genet. 138A, 282-287. doi: 10.1002/ajmg.a.30965

Kurima, K., Warman, M. L., Krishnan, S., Domowicz, M., Krueger, R. C. Jr., Deyrup, A., et al. (1998). A member of a family of sulfate-activating enzymes causes murine brachymorphism. Proc. Natl. Acad. Sci. U. S. A. 95, 8681-8685. doi: 10.1073/pnas.95.15.8681

Kuroda, Y., Murakami, H., Enomoto, Y., Tsurusaki, Y., Takahashi, K., Mitsuzuka, K., et al. (2019). A novel gene (FAM20B encoding glycosaminoglycan xylosylkinase) for neonatal short limb dysplasia resembling Desbuquois dysplasia. Clin. Genet. 95, 713-717. doi: 10.1111/cge.13530

Kusche-Gullberg, M., and Kjellén, L. (2003). Sulfotransferases in glycosaminoglycan biosynthesis. Curr. Opin. Struct. Biol. 13, 605-611. doi: 10.1016/j.sbi.2003.08.002

Laccone, F., Schoner, K., Krabichler, B., Kluge, B., Schwerdtfeger, R., Schulze, B., et al. (2011). Desbuquois dysplasia type I and fetal hydrops due to novel mutations in the CANT1 gene. Eur. J. Hum. Genet. 19, 1133-1137.

LaCroix, A. J., Stabley, D., Sahraoui, R., Adam, M. P., Mehaffey, M., Kernan, K., et al. (2019). GGC repeat expansion and exon 1 methylation of XYLT1 is a common pathogenic variant in Baratela-Scott syndrome. Am. J. Hum. Genet. 104, 35-44. doi: 10.1016/j.ajhg.2018.11.005

Larsen, L. J., Schottstaedt, E. R., and Bost, F. C. (1950). Multiple congenital dislocations associated with characteristic facial abnormality. J. Pediat. 37, 574-581. doi: 10.1016/s0022-3476(50)80268-8

Lautrup, C. K., Teik, K. W., Unzaki, A., Mizumoto, S., Syx, D., Sin, H. H., et al. (2020). Delineation of musculocontractural Ehlers-Danlos syndrome caused by dermatan sulfate epimerase deficiency. Mol. Genet. Genomic Med. 8:e1197. doi: $10.1002 / \mathrm{mgg} 3.1197$

Lee, J. S., von der Hardt, S., Rusch, M. A., Stringer, S. E., Stickney, H. L., Talbot, W. S., et al. (2004). Axon sorting in the optic tract requires HSPG synthesis by ext2 (dackel) and extl3 (boxer). Neuron 44, 947-960.

Li, Y., Laue, K., Temtamy, S., Aglan, M., Kotan, L. D., Yigit, G., et al. (2010). Temtamy preaxial brachydactyly syndrome is caused by loss-of-function mutations in chondroitin synthase 1, a potential target of BMP signaling. Am. J. Hum. Genet. 87, 757-767. doi: 10.1016/j.ajhg.2010.10.003

Lind, T., Tufaro, F., McCormick, C., Lindahl, U., and Lidholt, K. (1998). The putative tumor suppressors EXT1 and EXT2 are glycosyltransferases required for the biosynthesis of heparan sulfate. J. Biol. Chem. 273, 26265-26268. doi: 10.1074/jbc.273.41.26265

Lüdecke, H. J., Wagner, M. J., Nardmann, J., La Pillo, B., Parrish, J. E., Willems, P. J., et al. (1995). Molecular dissection of a contiguous gene syndrome: localization of the genes involved in the Langer-Giedion syndrome. Hum. Mol. Genet. 4, 31-36. doi: 10.1093/hmg/4.1.31

Maccarana, M., Olander, B., Malmström, J., Tiedemann, K., Aebersold, R., Lindahl, U., et al. (2006). Biosynthesis of dermatan sulfate: chondroitin-glucuronate C5-epimerase is identical to SART2. J. Biol. Chem. 281, 11560-11568.

Malfait, F., Castori, M., Francomano, C. A., Giunta, C., Kosho, T., and Byers, P. H. (2020). The Ehlers-Danlos syndromes. Nat. Rev. Dis. Primers 6:64. doi: 10.1038/s41572-020-0194-9

Malfait, F., Francomano, C., Byers, P., Belmont, J., Berglund, B., Black, J., et al. (2017). The 2017 international classification of the Ehlers-Danlos syndromes. Am. J. Med. Genet. C Semin. Med. Genet. 175, 8-26. doi: 10.1002/ajmg.c.31552

Malfait, F., Kariminejad, A., Van Damme, T., Gauche, C., Syx, D., MerhiSoussi, F., et al. (2013). Defective initiation of glycosaminoglycan synthesis due to B3GALT6 mutations causes a pleiotropic Ehlers-Danlos-syndrome-like connective tissue disorder. Am. J. Hum. Genet. 92, 935-945. doi: 10.1016/j.ajhg. 2013.04.016

Malfait, F., Syx, D., Vlummens, P., Symoens, S., Nampoothiri, S., Hermanns-Lê, T., et al. (2010). Musculocontractural Ehlers-Danlos Syndrome (former EDS type VIB) and adducted thumb clubfoot syndrome (ATCS) represent a single clinical entity caused by mutations in the dermatan-4-sulfotransferase 1 encoding CHST14 gene. Hum. Mutat. 31, 1233-1239. doi: 10.1002/humu.21355

Maselli, R. A., Fernandez, J. M., Arredondo, J., Navarro, C., Ngo, M., Beeson, D., et al. (2012). LG2 agrin mutation causing severe congenital myasthenic syndrome mimics functional characteristics of non-neural (z-) agrin. Hum Genet. 131, 1123-1135. doi: 10.1007/s00439-011-1132-4

McBrien, J., Crolla, J. A., Huang, S., Kelleher, J., Gleeson, J., and Lynch, S. A. (2008). Further case of microdeletion of $8 \mathrm{q} 24$ with phenotype overlapping LangerGiedion without TRPS1 deletion. Am. J. Med. Genet. A 146A, 1587-1592. doi: 10.1002/ajmg.a.32347

McCormick, C., Leduc, Y., Martindale, D., Mattison, K., Esford, L. E., Dyer, A. P., et al. (1998). The putative tumour suppressor EXT1 alters the expression of cell-surface heparan sulfate. Nat. Genet. 19, 158-161. doi: 10.1038/514

McTague, A., Howell, K. B., Cross, J. H., Kurian, M. A., and Scheffer, I. E. (2016). The genetic landscape of the epileptic encephalopathies of infancy and childhood. Lancet Neurol. 15, 304-316. doi: 10.1016/s1474-4422(15)00250-1

Meester, J. A., Vandeweyer, G., Pintelon, I., Lammens, M., Van Hoorick, L., De Belder, S., et al. (2017). Loss-of-function mutations in the X-linked biglycan gene cause a severe syndromic form of thoracic aortic aneurysms and dissections. Genet. Med. 19, 386-395. doi: 10.1038/gim.2016.126

Melrose, J. (2020). Perlecan, a modular instructive proteoglycan with diverse functional properties. Int. J. Biochem. Cell Biol. 128:105849. doi: 10.1016/j. biocel.2020.105849

Menzies, L., Cullup, T., Calder, A., Wilson, L., and Faravelli, F. (2019). A novel homozygous variant in CANT1 in a patient with Kim-type Desbuquois dysplasia. Clin. Dysmorphol. 28, 219-223. doi: 10.1097/mcd.0000000000000291

Mihalic Mosher, T., Zygmunt, D. A., Koboldt, D. C., Kelly, B. J., Johnson, L. R., McKenna, D. S., et al. (2019). Expansion of B4GALT7 linkeropathy phenotype to include perinatal lethal skeletal dysplasia. Eur. J. Hum. Genet. 27, 1569-1577. doi: 10.1038/s41431-019-0464-8

Mikami, T., Mizumoto, S., Kago, N., Kitagawa, H., and Sugahara, K. (2003). Specificities of three distinct human chondroitin/dermatan $\mathrm{N}$-acetylgalactosamine 4-O-sulfotransferases demonstrated using partially desulfated dermatan sulfate as an acceptor: implication of differential roles in dermatan sulfate biosynthesis. J. Biol. Chem. 278, 36115-36127. doi: 10.1074/jbc.m306044200

Millar, A. C., Faghfoury, H., and Bieniek, J. M. (2021). Genetics of hypogonadotropic hypogonadism. Transl. Androl. Urol. 10, 1401-1409.

Miraoui, H., Dwyer, A. A., Sykiotis, G. P., Plummer, L., Chung, W., Feng, B., et al. (2013). Mutations in FGF17, IL17RD, DUSP6, SPRY4, and FLRT3 are identified in individuals with congenital hypogonadotropic hypogonadism. Am. J. Hum. Genet. 92, 725-743.

Miyake, N., de Oliveira Stephan, B., Kim, C. A., and Matsumoto, N. (2021). A Brazilian case arising from a homozygous canonical splice site SLC35A3 variant 
leading to an in-frame deletion. Clin. Genet. 99, 607-608. doi: 10.1111/cge. 13909

Miyake, N., Elcioglu, N. H., Iida, A., Isguven, P., Dai, J., Murakami, N., et al. (2012). PAPSS2 mutations cause autosomal recessive brachyolmia. J. Med. Genet. 49, 533-538.

Miyake, N., Kosho, T., Mizumoto, S., Furuichi, T., Hatamochi, A., Nagashima, Y., et al. (2010). Loss-of-function mutations of CHST14 in a new type of Ehlers-Danlos syndrome. Hum. Mutat. 31, 966-974.

Miyamoto, T., Inoue, H., Sakamoto, Y., Kudo, E., Naito, T., Mikawa, T., et al. (2005). Identification of a novel splice site mutation of the CSPG2 gene in a Japanese family with Wagner syndrome. Invest. Ophthalmol. Vis. Sci. 46, 2726-2735. doi: 10.1167/iovs.05-0057

Mizumoto, S. (2018). Defects in biosynthesis of glycosaminoglycans cause hereditary bone, skin, heart, immune, and neurological disorders. Trends Glycosci. Glycotechnol. 30, E67-E89.

Mizumoto, S., Ikegawa, S., and Sugahara, K. (2013). Human genetic disorders caused by mutations in genes encoding biosynthetic enzymes for sulfated glycosaminoglycans. J. Biol. Chem. 288, 10953-10961.

Mizumoto, S., Janecke, A. R., Sadeghpour, A., Povysil, G., McDonald, M. T., Unger, S., et al. (2020). CSGALNACT1-congenital disorder of glycosylation: A mild skeletal dysplasia with advanced bone age. Hum. Mutat. 41, 655-667. doi: 10.1002/humu.23952

Mizumoto, S., Yamada, S., and Sugahara, K. (2014). Human genetic disorders and knockout mice deficient in glycosaminoglycan. Biomed Res. Int. 2014:495764. doi: 10.1155/2014/495764

Mizumoto, S., Yamada, S., and Sugahara, K. (2015a). Molecular interactions between chondroitin-dermatan sulfate and growth factors/receptors/matrix proteins. Curr. Opin. Struct. Biol. 34, 35-42.

Mizumoto, S., Yamada, S., and Sugahara, K. (2015b). Mutations in biosynthetic enzymes for the protein linker region of chondroitin/dermatan/heparan sulfate cause skeletal and skin dysplasias. Biomed. Res. Int. 2015:861752. doi: 10.1155/ 2015/861752

Moriarity, J. L., Hurt, K. J., Resnick, A. C., Storm, P. B., Laroy, W., Schnaar, R. L., et al. (2002). UDP-glucuronate decarboxylase, a key enzyme in proteoglycan synthesis. J. Biol. Chem. 277, 16968-16975. doi: 10.1074/jbc.m109316200

Mortier, G. R., Cohn, D. H., Cormier-Daire, V., Hall, C., Krakow, D., Mundlos, S., et al. (2019). Nosology and classification of genetic skeletal disorders: 2019 revision. Am. J. Med. Genet. A 179, 2393-2419. doi: 10.1002/ajmg.a.61366

Müller, T., Mizumoto, S., Suresh, I., Komatsu, Y., Vodopiutz, J., Dundar, M., et al. (2013). Loss of dermatan sulfate epimerase (DSE) function results in musculocontractural Ehlers-Danlos syndrome. Hum. Mol. Genet. 22, 37613772. doi: $10.1093 / \mathrm{hmg} / \mathrm{ddt} 227$

Munns, C. F., Fahiminiya, S., Poudel, N., Munteanu, M. C., Majewski, J., Sillence, D. O., et al. (2015). Homozygosity for frameshift mutations in XYLT2 result in a spondylo-ocular syndrome with bone fragility, cataracts, and hearing defects. Am. J. Hum. Genet. 96, 971-978. doi: 10.1016/j.ajhg.2015. 04.017

Muraoka, M., Kawakita, M., and Ishida, N. (2001). Molecular characterization of human UDP-glucuronic acid/UDP- $N$-acetylgalactosamine transporter, a novel nucleotide sugar transporter with dual substrate specificity. FEBS Lett. 495, 87-93. doi: 10.1016/s0014-5793(01)02358-4

Muys, J., Blaumeiser, B., Jacquemyn, Y., and Janssens, K. (2016). Prenatal homozygosity mapping detects a novel mutation in CHST3 in a fetus with skeletal dysplasia and joint dislocations. Clin. Case Rep. 5, 440-445. doi: 10. $1002 /$ ccr3.800

Najmabadi, H., Hu, H., Garshasbi, M., Zemojtel, T., Abedini, S. S., Chen, W., et al. (2011). Deep sequencing reveals 50 novel genes for recessive cognitive disorders. Nature 478, 57-63.

Nakajima, M., Mizumoto, S., Miyake, N., Kogawa, R., Iida, A., Ito, H., et al. (2013). Mutations in B3GALT6, which encodes a glycosaminoglycan linker region enzyme, cause a spectrum of skeletal and connective tissue disorders. Am. J. Hum. Genet. 92, 927-934. doi: 10.1016/j.ajhg.2013.04.003

Nakao, M., Shichijo, S., Imaizumi, T., Inoue, Y., Matsunaga, K., Yamada, A., et al. (2000). Identification of a gene coding for a new squamous cell carcinoma antigen recognized by the CTL. J. Immunol. 164, 2565-2574. doi: 10.4049/ jimmunol.164.5.2565
Narentuya, Takeda-Uchimura, Y., Foyez, T., Zhang, Z., Akama, T. O., Yagi, H., et al. (2019). GlcNAc6ST3 is a keratan sulfate sulfotransferase for the proteintyrosine phosphatase PTPRZ in the adult brain. Sci. Rep. 9:4387. doi: 10.1038/ s41598-019-40901-2

Nicole, S., Davoine, C. S., Topaloglu, H., Cattolico, L., Barral, D., Beighton, P., et al. (2000). Perlecan, the major proteoglycan of basement membranes, is altered in patients with Schwartz-Jampel syndrome (chondrodystrophic myotonia). Nat. Genet. 26, 480-483. doi: 10.1038/82638

Nikkels, P. G., Stigter, R. H., Knol, I. E., and van der Harten, H. J. (2001). Schneckenbecken dysplasia, radiology, and histology. Pediatr. Radio. 31, 27-30. doi: $10.1007 / \mathrm{s} 002470000357$

Nizon, M., Alanay, Y., Tuysuz, B., Kiper, P. O., Geneviève, D., Sillence, D., et al. (2012a). IMPAD1 mutations in two Catel-Manzke like patients. Am. J. Med. Genet. A 158A, 2183-2187. doi: 10.1002/ajmg.a.35504

Nizon, M., Huber, C., De Leonardis, F., Merrina, R., Forlino, A., Fradin, M., et al. (2012b). Further delineation of CANT1 phenotypic spectrum and demonstration of its role in proteoglycan synthesis. Hum. Mutat. 33, 12611266. doi: 10.1002/humu.22104

Noordam, C., Dhir, V., McNelis, J. C., Schlereth, F., Hanley, N. A., Krone, N., et al. (2009). Inactivating PAPSS2 mutations in a patient with premature pubarche. N. Engl. J. Med. 360, 2310-2318.

Oh, S. P., Kamagata, Y., Muragaki, Y., Timmons, S., Ooshima, A., and Olsen, B. R. (1994). Isolation and sequencing of cDNAs for proteins with multiple domains of Gly-Xaa-Yaa repeats identify a distinct family of collagenous proteins. Proc. Natl. Acad. Sci. U. S. A 91, 4229-4233. doi: 10.1073/pnas.91.10.4229

Okajima, T., Yoshida, K., Kondo, T., and Furukawa, K. (1999). Human homolog of Caenorhabditis elegans sqv-3 gene is galactosyltransferase I involved in the biosynthesis of the glycosaminoglycan-protein linkage region of proteoglycans. J. Biol. Chem. 274, 22915-22918. doi: 10.1074/jbc.274.33.22915

Oud, M. M., Tuijnenburg, P., Hempel, M., van Vlies, N., Ren, Z., Ferdinandusse, S., et al. (2017). Mutations in EXTL3 cause neuro-immuno-skeletal dysplasia syndrome. Am. J. Hum. Genet. 100, 281-296.

Pacheco, B., Malmström, A., and Maccarana, M. (2009). Two dermatan sulfate epimerases form iduronic acid domains in dermatan sulfate. J. Biol. Chem. 284, 9788-9795. doi: 10.1074/jbc.m809339200

Palka, C., Alfonsi, M., Mohn, A., Guanciali Franchi, P., Chiarelli, F., and Calabrese, G. (2012). Delayed diagnosis of Potocki-Shaffer syndrome in a woman with multiple exostoses and mental retardation. Mol. Syndromol. 2, 259-261. doi: $10.1159 / 000337925$

Pellegata, N. S., Dieguez-Lucena, J. L., Joensuu, T., Lau, S., Montgomery, K. T., Krahe, R., et al. (2000). Mutations in KERA, encoding keratocan, cause cornea plana. Nat. Genet. 25, 91-95. doi: 10.1038/75664

Pennypacker, J. P., Kimata, K., and Brown, K. S. (1981). Brachymorphic mice (bm/bm): a generalized biochemical defect expressed primarily cartilage. Dev. Biol. 81, 280-287. doi: 10.1016/0012-1606(81)90291-8

Pereza, N., Severinski, S., Ostojić, S., Volk, M., Maver, A., Dekanić, K. B., et al. (2012). Third case of 8q23.3-q24.13 deletion in a patient with Langer-Giedion syndrome phenotype without TRPS1 gene deletion. Am. J. Med. Genet. A 158A, 659-663. doi: 10.1002/ajmg.a.35201

Philippe, C., Porter, D. E., Emerton, M. E., Wells, D. E., Simpson, A. H., and Monaco, A. P. (1997). Mutation screening of the EXT1 and EXT2 genes in patients with hereditary multiple exostoses. Am. J. Hum. Genet. 61, 520-528. doi: 10.1086/515505

Pönighaus, C., Ambrosius, M., Casanova, J. C., Prante, C., Kuhn, J., Esko, J. D., et al. (2007). Human xylosyltransferase II is involved in the biosynthesis of the uniform tetrasaccharide linkage region in chondroitin sulfate and heparan sulfate proteoglycans. J. Biol. Chem. 282, 5201-5206. doi: 10.1074/jbc. m611665200

Quentin, E., Gladen, A., Rodén, L., and Kresse, H. (1990). A genetic defect in the biosynthesis of dermatan sulfate proteoglycan: galactosyltransferase I deficiency in fibroblasts from a patient with a progeroid syndrome. Proc. Natl. Acad. Sci. U. S. A. 87, 1342-1346. doi: 10.1073/pnas.87.4.1342

Rajab, A., Kornak, U., Budde, B. S., Hoffmann, K., Jaeken, J., Nürnberg, P., et al. (2008). Geroderma osteodysplasticum hereditaria and wrinkly skin syndrome in 22 patients from Oman. Am. J. Med. Genet. A. 146A, 965-976. 
Rajab, A., Kunze, J., and Mundlos, S. (2004). Spondyloepiphyseal dysplasia Omani type: a new recessive type of SED with progressive spinal involvement. Am. J. Med. Genet. 126A, 413-419. doi: 10.1002/ajmg.a.20606

Reuter, M. S., Musante, L., Hu, H., Diederich, S., Sticht, H., Ekici, A. B., et al. (2014). NDST1 missense mutations in autosomal recessive intellectual disability. Am. J. Med. Genet. A 164A, 2753-2763.

Ritelli, M., Chiarelli, N., Zoppi, N., Dordoni, C., Quinzani, S., Traversa, M., et al. (2014). Insights in the etiopathology of galactosyltransferase II (GalT-II) deficiency from transcriptome-wide expression profiling of skin fibroblasts of two sisters with compound heterozygosity for two novel B3GALT6 mutations. Mol. Genet. Metab. Rep. 2, 1-15. doi: 10.1016/j.ymgmr.2014.11.005

Ritelli, M., Dordoni, C., Cinquina, V., Venturini, M., Calzavara-Pinton, P., and Colombi, M. (2017). Expanding the clinical and mutational spectrum of B4GALT7-spondylodysplastic Ehlers-Danlos syndrome. Orphanet. J. Rare Dis. 12:153. doi: 10.1186/s13023-017-0704-3

Rødahl, E., Van Ginderdeuren, R., Knappskog, P. M., Bredrup, C., and Boman, H. (2006). A second decorin frame shift mutation in a family with congenital stromal corneal dystrophy. Am. J. Ophthalmol. 142, 520-521. doi: 10.1016/j. ajo.2006.03.064

Rossi, A., and Superti-Furga, A. (2001). Mutations in the diastrophic dysplasia sulfate transporter (DTDST) gene (SLC26A2): 22 novel mutations, mutation review, associated skeletal phenotypes, and diagnostic relevance. Hum. Mutat. 17, 159-171. doi: 10.1002/humu.1

Rupp, F., Ozçelik, T., Linial, M., Peterson, K., Francke, U., and Scheller, R. (1992). Structure and chromosomal localization of the mammalian agrin gene. J. Neurosci. 12, 3535-3544. doi: 10.1523/jneurosci.12-09-03535.1992

Rupp, F., Payan, D. G., Magill-Solc, C., Cowan, D. M., and Scheller, R. H. (1991). Structure and expression of a rat agrin. Neuron 6, 811-823. doi: 10.1016/08966273(91)90177-2

Sakazume, S., Okamoto, N., Yamamoto, T., Kurosawa, K., Numabe, H., Ohashi, Y., et al. (2007). GPC3 mutations in seven patients with Simpson-Golabi-Behmel syndrome. Am. J. Med. Genet. A 143A, 1703-1707. doi: 10.1002/ajmg.a.31822

Salter, C. G., Davies, J. H., Moon, R. J., Fairhurst, J., Bunyan, D., Ddd Study, et al. (2016). Further defining the phenotypic spectrum of B4GALT7 mutations. Am. J. Med. Genet. A 170, 1556-1563.

Satoh, H., Susaki, M., Shukunami, C., Iyama, K., Negoro, T., and Hiraki, Y. (1998). Functional analysis of diastrophic dysplasia sulfate transporter. Its involvement in growth regulation of chondrocytes mediated by sulfated proteoglycans. J. Biol. Chem. 273, 12307-12315. doi: 10.1074/jbc.273.20. 12307

Saul, R. A., and Wilson, W. G. (1990). A“new"skeletaldysplasia in two unrelated boys. Am. J. Med. Genet. 35, 388-393. doi: 10.1002/ajmg.1320350315

Schneeberger, P. E., von Elsner, L., Barker, E. L., Meinecke, P., Marquardt, I., Alawi, M., et al. (2020). Bi-allelic pathogenic variants in HS2ST1 cause a syndrome characterized by developmental delay and corpus callosum, skeletal, and renal abnormalities. Am. J. Hum. Genet. 107, 1044-1061. doi: 10.1016/j.ajhg.2020.10. 007

Schreml, J., Durmaz, B., Cogulu, O., Keupp, K., Beleggia, F., Pohl, E., et al. (2014). The missing "link": an autosomal recessive short stature syndrome caused by a hypofunctional XYLT1 mutation. Hum. Genet. 133, 29-39. doi: 10.1007/ s00439-013-1351-y

Seidler, D. G., Faiyaz-Ul-Haque, M., Hansen, U., Yip, G. W., Zaidi, S. H., Teebi, A. S., et al. (2006). Defective glycosylation of decorin and biglycan, altered collagen structure, and abnormal phenotype of the skin fibroblasts of an Ehlers-Danlos syndrome patient carrying the novel Arg270Cys substitution in galactosyltransferase I ( $\beta 4$ GalT-7). J. Mol. Med. (Berl.) 84, 583-594. doi: 10.1007/s00109-006-0046-4

Seidler, U., and Nikolovska, K. (2019). Slc26 family of anion transporters in the gastrointestinal tract: expression, function, regulation, and role in disease. Compr. Physiol. 9, 839-872. doi: 10.1002/cphy.c180027

Seko, A., Dohmae, N., Takio, K., and Yamashita, K. (2003). B1,4Galactosyltransferase ( $\beta 4 \mathrm{GalT}$ )-IV is specific for GlcNAc 6-O-sulfate. $\beta 4 \mathrm{GalT}-\mathrm{IV}$ acts on keratan sulfate-related glycans and a precursor glycan of 6-sulfosialyl-Lewis X. J. Biol. Chem. 278, 9150-9158. doi: $10.1074 /$ jbc.m211480200

Seko, A., and Yamashita, K. (2004). B1,3-N-Acetylglucosaminyltransferase-7 $(\beta 3 \mathrm{Gn}-\mathrm{T} 7)$ acts efficiently on keratan sulfate-related glycans. FEBS Lett. 556, 216-220. doi: 10.1016/s0014-5793(03)01440-6
Sertié, A. L., Sossi, V., Camargo, A. A., Zatz, M., Brahe, C., and Passos-Bueno, M. R. (2000). Collagen XVIII, containing an endogenous inhibitor of angiogenesis and tumor growth, plays a critical role in the maintenance of retinal structure and in neural tube closure (Knobloch syndrome). Hum. Mol. Genet. 9, 20512058. doi: 10.1093/hmg/9.13.2051

Shabbir, R. M. K., Nalbant, G., Ahmad, N., Malik, S., and Tolun, A. (2018). Homozygous CHST11 mutation in chondrodysplasia, brachydactyly, overriding digits, clino-symphalangism and synpolydactyly. J. Med. Genet. 55, 489-496. doi: 10.1136/jmedgenet-2017-105003

Sher, G., and Naeem, M. (2014). A novel CHSY1 gene mutation underlies Temtamy preaxial brachydactyly syndrome in a Pakistani family. Eur. J. Med. Genet. 57, 21-24. doi: 10.1016/j.ejmg.2013.11.001

Shi, J., Potash, J. B., Knowles, J. A., Weissman, M. M., Coryell, W., Scheftner, W. A., et al. (2011). Genome-wide association study of recurrent early-onset major depressive disorder. Mol. Psychiatry 16, 193-201.

Silveira, C., Leal, G. F., and Cavalcanti, D. P. (2016). Desbuquois dysplasia type II in a patient with a homozygous mutation in XYLT1 and new unusual findings. Am. J. Med. Genet. A 170, 3043-3047. doi: 10.1002/ajmg.a.37858

Singh, A., Kim, O. H., Iida, A., Park, W. Y., Ikegawa, S., and Kapoor, S. (2015). A novel CANT1 mutation in three Indian patients with Desbuquois dysplasia kim type. Eur. J. Med. Genet. 58, 105-110. doi: 10.1016/j.ejmg.2014.11.006

Smith, T. M., Hicks-Berger, C. A., Kim, S., and Kirley, T. L. (2002). Cloning, expression, and characterization of a soluble calcium-activated nucleotidase, a human enzyme belonging to a new family of extracellular nucleotidases. Arch. Biochem. Biophys. 406, 105-115. doi: 10.1016/s0003-9861(02)00420-4

Solomon, L. (1963). Hereditary multiple exostosis. J. Bone Joint Surg. Br. 45, 292-304.

Sonoda, T., and Kouno, K. (2000). Two brothers with distal arthrogryposis, peculiar facial appearance, cleft palate, short stature, hydronephrosis, retentio testis, and normal intelligence: a new type of distal arthrogryposis? Am. J. Med. Genet. 91, 280-285. doi: 10.1002/(sici)1096-8628(20000410)91:4<280:: aid-ajmg8 $>3.0$. co;2-b

Spicer, A. P., Kaback, L. A., Smith, T. J., and Seldin, M. F. (1998). Molecular cloning and characterization of the human and mouse UDP-glucose dehydrogenase genes. J. Biol. Chem. 273, 25117-25124. doi: 10.1074/jbc.273.39.25117

Srivastava, P., Pandey, H., Agarwal, D., Mandal, K., and Phadke, S. R. (2017). Spondyloepiphyseal dysplasia Omani type: CHST3 mutation spectrum and phenotypes in three Indian families. Am. J. Med. Genet. A 173, 163-168. doi: 10.1002/ajmg.a.37996

Stattin, E. L., Wiklund, F., Lindblom, K., Onnerfjord, P., Jonsson, B. A., Tegner, Y., et al. (2010). A missense mutation in the aggrecan C-type lectin domain disrupts extracellular matrix interactions and causes dominant familial osteochondritis dissecans. Am. J. Hum. Genet. 86, 126-137. doi: 10.1016/j.ajhg.2009.12.018

Stickens, D., Clines, G., Burbee, D., Ramos, P., Thomas, S., Hogue, D., et al. (1996). The EXT2 multiple exostoses gene defines a family of putative tumour suppressor genes. Nat. Genet. 14, 25-32. doi: 10.1038/ng0996-25

Stum, M., Davoine, C. S., Vicart, S., Guillot-Noël, L., Topaloglu, H., Carod-Artal, F. J., et al. (2006). Spectrum of HSPG2 (Perlecan) mutations in patients with Schwartz-Jampel syndrome. Hum. Mutat. 27, 1082-1091. doi: 10.1002/humu. 20388

Sugahara, K., and Kitagawa, H. (2000). Recent advances in the study of the biosynthesis and functions of sulfated glycosaminoglycans. Curr. Opin. Struct. Biol. 10, 518-527. doi: 10.1016/s0959-440x(00)00125-1

Sugahara, K., and Schwartz, N. B. (1979). Defect in 3'-phosphoadenosine 5'phosphosulfate formation in brachymorphic mice. Proc. Natl. Acad. Sci. U. S. A. 76, 6615-6618. doi: 10.1073/pnas.76.12.6615

Sultana, A., Sridhar, M. S., Klintworth, G. K., Balasubramanian, D., and Kannabiran, C. (2005). Allelic heterogeneity of the carbohydrate sulfotransferase- 6 gene in patients with macular corneal dystrophy. Clin. Genet. 68, 454-460. doi: 10.1111/j.1399-0004.2005.00517.x

Superti-Furga, A., Hästbacka, J., Wilcox, W. R., Cohn, D. H., van der Harten, H. J., Rossi, A., et al. (1996). Achondrogenesis type IB is caused by mutations in the diastrophic dysplasia sulphate transporter gene. Nat. Genet. 12, 100-102. doi: $10.1038 / \mathrm{ng} 0196-100$

Suzuki, O. T., Sertié, A. L., Der Kaloustian, V. M., Kok, F., Carpenter, M., Murray, J., et al. (2002). Molecular analysis of collagen XVIII reveals novel mutations, presence of a third isoform, and possible genetic heterogeneity in Knobloch syndrome. Am. J. Hum. Genet. 71, 1320-1329. doi: 10.1086/344695 
Swarr, D. T., Bloom, D., Lewis, R. A., Elenberg, E., Friedman, E. M., Glotzbach, C., et al. (2010). Potocki-Shaffer syndrome: comprehensive clinical assessment, review of the literature, and proposals for medical management. Am. J. Med. Genet. A 152A, 565-572. doi: 10.1002/ajmg.a.33245

Syx, D., Van Damme, T., Symoens, S., Maiburg, M. C., van de Laar, I., Morton, J., et al. (2015). Genetic heterogeneity and clinical variability in musculocontractural Ehlers-Danlos syndrome caused by impaired dermatan sulfate biosynthesis. Hum. Mutat. 36, 535-547. doi: 10.1002/humu.22774

Szulc, B., Sosicka, P., Maszczak-Seneczko, D., Skurska, E., Shauchuk, A., Olczak, T., et al. (2020). Biosynthesis of GlcNAc-rich $N$ - and O-glycans in the Golgi apparatus does not require the nucleotide sugar transporter SLC35A3. J. Biol. Chem. 295, 16445-16463. doi: 10.1074/jbc.ra119.012362

Tahvanainen, E., Forsius, H., Kolehmainen, J., Damsten, M., Fellman, J., and de la Chapelle, A. (1996). The genetics of cornea plana congenita. J. Med. Genet. 33, 116-119. doi: 10.1136/jmg.33.2.116

Takeda, R., Takagi, M., Shinohara, H., Futagawa, H., Narumi, S., Hasegawa, T., et al. (2017). Novel compound heterozygous mutations identified by whole exome sequencing in a Japanese patient with geroderma osteodysplastica. Eur. J. Med. Genet. 60, 635-638. doi: 10.1016/j.ejmg.2017.08.002

Tanteles, G. A., Dixit, A., Dhar, S., and Surim, M. (2013). Two Somali half-siblings with CHST3-related chondrodysplasia illustrating the phenotypic spectrum and intrafamilial variability. Am. J. Med. Genet. A 161A, 2588-2593.

Taylan, F., Costantini, A., Coles, N., Pekkinen, M., Héon, E., Şıklar, Z., et al. (2016). Spondyloocular syndrome: novel mutations in XYLT2 gene and expansion of the phenotypic spectrum. J. Bone Miner. Res. 31, 1577-1585. doi: 10.1002/jbmr. 2834

Taylan, F., Yavaş Abalı, Z., Jäntti, N., Güneş, N., Darendeliler, F., Baş, F., et al. (2017). Two novel mutations in XYLT2 cause spondyloocular syndrome. Am. J. Med. Genet. A 173, 3195-3200. doi: 10.1002/ajmg.a.38470

Temtamy, S., Aglan, M., Topaloglu, A. K., Wollnik, B., Amr, K., El-Badry, T. H., et al. (2012). Definition of the phenotypic spectrum of Temtamy preaxial brachydactyly syndrome associated with autosomal recessive CHYS1 mutations. Middle East J. Med. Genet. 1, 64-70. doi: 10.1097/01.mxe. 0000414918.78299 .94

Temtamy, S. A., Meguid, N. A., Ismail, S. I., and Ramzy, M. I. (1998). A new multiple congenital anomaly, mental retardation syndrome with preaxial brachydactyly, hyperphalangism, deafness and orodental anomalies. Clin. Dysmorph. 7, 249-255. doi: 10.1097/00019605-199810000-00003

Thelin, M. A., Bartolini, B., Axelsson, J., Gustafsson, R., Tykesson, E., Pera, E., et al. (2013). Biological functions of iduronic acid in chondroitin/dermatan sulfate. FEBS J. 280, 2431-2446. doi: 10.1111/febs.12214

Thiele, H., Sakano, M., Kitagawa, H., Sugahara, K., Rajab, A., Höhne, W., et al. (2004). Loss of chondroitin 6-O-sulfotransferase-1 function results in severe human chondrodysplasia with progressive spinal involvement. Proc. Natl. Acad. Sci. U. S. A. 101, 10155-10160. doi: 10.1073/pnas.0400334101

Thoden, J. B., Wohlers, T. M., Fridovich-Keil, J. L., and Holden, H. M. (2001). Human UDP-galactose 4-epimerase. Accommodation of UDP- $N$ acetylglucosamine within the active site. J. Biol. Chem. 276, 15131-15136.

Tian, J., Ling, L., Shboul, M., Lee, H., O’Connor, B., Merriman, B., et al. (2010). Loss of CHSY1, a secreted FRINGE enzyme, causes syndromic brachydactyly in humans via increased NOTCH signaling. Am. J. Hum. Genet. 87, 768-778. doi: 10.1016/j.ajhg.2010.11.005

Tompson, S. W., Merriman, B., Funari, V. A., Fresquet, M., Lachman, R. S., Rimoin, D. L., et al. (2009). A recessive skeletal dysplasia, SEMD aggrecan type, results from a missense mutation affecting the C-type lectin domain of aggrecan. Am. J. Hum. Genet. 84, 72-79. doi: 10.1016/j.ajhg.2008.12.001

Tone, Y., Pedersen, L. C., Yamamoto, T., Izumikawa, T., Kitagawa, H., Nishihara, J., et al. (2008). 2-O-phosphorylation of xylose and 6-O-sulfation of galactose in the protein linkage region of glycosaminoglycans influence the glucuronyltransferase-I activity involved in the linkage region synthesis. J. Biol. Chem. 283, 16801-16807. doi: 10.1074/jbc.m709556200

Tornberg, J., Sykiotis, G. P., Keefe, K., Plummer, L., Hoang, X., Hall, J. E., et al. (2011). Heparan sulfate 6-O-sulfotransferase 1, a gene involved in extracellular sugar modifications, is mutated in patients with idiopathic hypogonadotrophic hypogonadism. Proc. Natl. Acad. Sci. U. S. A. 108, 11524-11529. doi: 10.1073/ pnas. 1102284108

Tuysuz, B., Mizumoto, S., Sugahara, K., Celebi, A., Mundlos, S., and Turkmen, S. (2009). Omani-type spondyloepiphyseal dysplasia with cardiac involvement caused by a missense mutation in CHST3. Clin. Genet. 75, 375-383. doi: 10.1111/j.1399-0004.2009.01167.x

Tüysüz, B., Yılmaz, S., Gül, E., Kolb, L., Bilguvar, K., Evliyaoğlu, O., et al. (2013). Spondyloepimetaphyseal dysplasia Pakistani type: expansion of the phenotype. Am. J. Med. Genet. A 161A, 1300-1308.

Umair, M., Eckstein, G., Rudolph, G., Strom, T., Graf, E., Hendig, D., et al. (2018). Homozygous XYLT2 variants as a cause of spondyloocular syndrome. Clin. Genet. 93, 913-918. doi: 10.1111/cge.13179

Unger, S., Lausch, E., Rossi, A., Mégarbané, A., Sillence, D., Alcausin, M., et al. (2010). Phenotypic features of carbohydrate sulfotransferase 3 (CHST3) deficiency in 24 patients: congenital dislocations and vertebral changes as principal diagnostic features. Am. J. Med. Genet. 152A, 2543-2549. doi: 10. 1002/ajmg.a.33641

Uyama, T., Kitagawa, H., Tamura, J., and Sugahara, K. (2002). Molecular cloning and expression of human chondroitin $\mathrm{N}$-acetylgalactosaminyltransferase: the key enzyme for chain initiation and elongation of chondroitin/dermatan sulfate on the protein linkage region tetrasaccharide shared by heparin/heparan sulfate. J. Biol. Chem. 277, 8841-8846.

Uyama, T., Kitagawa, H., Tanaka, J., Tamura, J., Ogawa, T., and Sugahara, K. (2003). Molecular cloning and expression of a second chondroitin $\mathrm{N}$-acetylgalactosaminyltransferase involved in the initiation and elongation of chondroitin/dermatan sulfate. J. Biol. Chem. 278, 3072-3078. doi: 10.1074/jbc. m209446200

Van Ginderdeuren, R., De Vos, R., Casteels, I., and Foets, B. (2002). Report of a new family with dominant congenital heredity stromal dystrophy of the cornea. Cornea 21, 118-120. doi: 10.1097/00003226-200201000-00025

Van Laer, L., Dietz, H., and Loeys, B. (2014). Loeys-Dietz syndrome. Adv. Exp. Med. Biol. 802, 95-105.

van Roij, M. H., Mizumoto, S., Yamada, S., Morgan, T., Tan-Sindhunata, M. B., Meijers-Heijboer, H., et al. (2008). Spondyloepiphyseal dysplasia, Omani type: further definition of the phenotype. Am. J. Med. Genet. A 146A, 2376-2384. doi: 10.1002/ajmg.a.32482

Venkatachalam, K. V. (2003). Human $3^{\prime}$-phosphoadenosine $5^{\prime}$-phosphosulfate (PAPS) synthase: biochemistry, molecular biology and genetic deficiency. IUBMB Life 55, 1-11.

Veugelers, M., Cat, B. D., Muyldermans, S. Y., Reekmans, G., Delande, N., Frints, S., et al. (2000). Mutational analysis of the GPC3/GPC4 glypican gene cluster on Xq26 in patients with Simpson-Golabi-Behmel syndrome: identification of loss-of-function mutations in the GPC3 gene. Hum. Mol. Genet. 9, 1321-1328. doi: $10.1093 / \mathrm{hmg} / 9.9 .1321$

Vissers, L. E., Lausch, E., Unger, S., Campos-Xavier, A. B., Gilissen, C., Rossi, A., et al. (2011). Chondrodysplasia and abnormal joint development associated with mutations in IMPAD1, encoding the Golgi-resident nucleotide phosphatase, gPAPP. Am. J. Hum. Genet. 88, 608-615. doi: 10.1016/j.ajhg.2011. 04.002

Vodopiutz, J., Mizumoto, S., Lausch, E., Rossi, A., Unger, S., Janocha, N., et al. (2017). Chondroitin sulfate N-acetylgalactosaminyltransferase-1 (CSGalNAcT1) deficiency results in a mild skeletal dysplasia and joint laxity. Hum. Mutat. 38, 34-38. doi: 10.1002/humu.23070

Volpi, S., Yamazaki, Y., Brauer, P. M., van Rooijen, E., Hayashida, A., Slavotinek, A., et al. (2017). EXTL3 mutations cause skeletal dysplasia, immune deficiency, and developmental delay. J. Exp. Med. 214, 623-637. doi: 10.1084/jem.201 61525

von Oettingen, J. E., Tan, W. H., and Dauber, A. (2014). Skeletal dysplasia, global developmental delay, and multiple congenital anomalies in a 5-year-old boyreport of the second family with B3GAT3 mutation and expansion of the phenotype. Am. J. Med. Genet. A 164A, 1580-1586. doi: 10.1002/ajmg.a.36487

Vorster, A. A., Beighton, P., and Ramesar, R. S. (2015). Spondyloepimetaphyseal dysplasia with joint laxity (Beighton type); mutation analysis in eight affected South African families. Clin. Genet. 87, 492-495. doi: 10.1111/cge.12413

Waryah, A. M., Shahzad, M., Shaikh, H., Sheikh, S. A., Channa, N. A., Hufnagel, R. B., et al. (2016). A novel CHST3 allele associated with spondyloepiphyseal dysplasia and hearing loss in Pakistani kindred. Clin. Genet. 90, 90-95. doi: $10.1111 /$ cge. 12694

Wuyts, W., Roland, D., Lüdecke, H. J., Wauters, J., Foulon, M., Van Hul, W., et al. (2002). Multiple exostoses, mental retardation, hypertrichosis, and brain abnormalities in a boy with a de novo 8q24 submicroscopic interstitial deletion. Am. J. Med. Genet. 113, 326-332. doi: 10.1002/ajmg.10845 
Wuyts, W., and Van Hul, W. (2000). Molecular basis of multiple exostoses: mutations in the EXT1 and EXT2 genes. Hum. Mutat. 15, 220-227. doi: 10.1002/(sici) 1098-1004(200003)15:3<220::aid-humu2>3.0.co;2-k

Wuyts, W., Van Hul, W., De Boulle, K., Hendrickx, J., Bakker, E., Vanhoenacker, F., et al. (1998). Mutations in the EXT1 and EXT2 genes in hereditary multiple exostoses. Am. J. Hum. Genet. 62, 346-354.

Yamauchi, S., Mita, S., Matsubara, T., Fukuta, M., Habuchi, H., Kimata, K., et al. (2000). Molecular cloning and expression of chondroitin 4-sulfotransferase. J. Biol. Chem. 275, 8975-8981. doi: 10.1074/jbc.275.12.8975

Yap, P., Liebelt, J. E., Amor, D. J., Moore, L., and Savarirayan, R. (2016). Pseudodiastrophic dysplasia: Two cases delineating and expanding the pre and postnatal phenotype. Am. J. Med. Genet. A 170A, 1363-1366. doi: 10.1002/ ajmg.a.37548

Yauy, K., Tran Mau-Them, F., Willems, M., Coubes, C., Blanchet, P., Herlin, C., et al. (2018). B3GAT3-related disorder with craniosynostosis and bone fragility due to a unique mutation. Genet. Med. 20, 269-274. doi: 10.1038/gim.2017.109

Yoshizawa, T., Mizumoto, S., Takahashi, Y., Shimada, S., Sugahara, K., Nakayama,

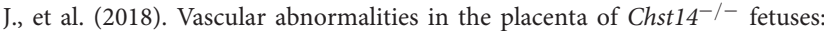
implications in the pathophysiology of perinatal lethality of the murine model and vascular lesions in human CHST14/D4ST1 deficiency. Glycobiology 28, 80-89. doi: 10.1093/glycob/cwx099

Zayed, H., Chao, R., Moshrefi, A., Lopezjimenez, N., Delaney, A., Chen, J., et al. (2010). A maternally inherited chromosome 18q22.1 deletion in a male with late-presenting diaphragmatic hernia and microphthalmia-evaluation of DSEL as a candidate gene for the diaphragmatic defect. Am. J. Med. Genet. 152A, 916-923. doi: 10.1002/ajmg.a.33341

Conflict of Interest: The authors declare that the research was conducted in the absence of any commercial or financial relationships that could be construed as a potential conflict of interest.

The handling editor declared a past co-authorship with the authors SM and SY.

Publisher's Note: All claims expressed in this article are solely those of the authors and do not necessarily represent those of their affiliated organizations, or those of the publisher, the editors and the reviewers. Any product that may be evaluated in this article, or claim that may be made by its manufacturer, is not guaranteed or endorsed by the publisher.

Copyright (c) 2021 Mizumoto and Yamada. This is an open-access article distributed under the terms of the Creative Commons Attribution License (CC BY). The use, distribution or reproduction in other forums is permitted, provided the original author(s) and the copyright owner(s) are credited and that the original publication in this journal is cited, in accordance with accepted academic practice. No use, distribution or reproduction is permitted which does not comply with these terms. 